\title{
TERMINAL PATTERNS OF SINGLE, PHYSIOLOGICALLY CHARACTERIZED OPTIC TRACT FIBERS IN THE CAT'S LATERAL GENICULATE NUCLEUS ${ }^{1}$
}

\author{
DOUGLAS B. BOWLING ${ }^{2}$ AND CHARLES R. MICHAEL \\ Department of Physiology, Yale University, School of Medicine, New Haven, Connecticut 06510
}

Received March 21, 1983; Revised July 29, 1983; Accepted August 19, 1983

\begin{abstract}
We have examined the patterns of termination of single, physiologically identified optic tract fibers in the dorsal lateral geniculate nucleus (LGNd) of the cat. The axons were impaled with a recording micropipette and characterized by their responses to light and by their conduction latencies to electrical stimulation of the optic nerve. Horseradish peroxidase was then iontophoretically injected from the pipette into the single fibers. Subsequent histological processing and serial reconstruction revealed the fibers' destinations, patterns of arborization, and the spatial distributions of their terminal boutons.

Axons classified as type $\mathrm{X}$ invariably projected to layer $\mathrm{A}$ or $\mathrm{A}_{1}$ of the LGNd and some sent a collateral into the medial interlaminar nucleus (MIN). Axons of the $\mathrm{Y}$ type terminated in layer A or $A_{1}$ and the MIN. Those from the contralateral eye nearly always had an additional termination in the magnocellular $\mathrm{C}$ layer, whereas those from the ipsilateral eye occasionally terminated in layer $\mathrm{C}_{1}$.

In the A layers axons distributed their terminal boutons in columns that spanned the widths of the layers. The columns differed in size, shape, and density depending on whether they were from $\mathrm{X}, \mathrm{Y}$-on, or Y-off axons. The columns from both $\mathrm{X}$-on and $\mathrm{X}$-off axons were narrow cylinders averaging about $150 \mu \mathrm{m}$ in width. The columns usually contained fewer than a thousand boutons and about $60 \%$ of the boutons were concentrated in the upper halves of the layers. The Y columns were wider, averaging about $375 \mu \mathrm{m}$ in width, and contained around 1500 boutons. About $70 \%$ of the $\mathrm{Y}$ boutons were concentrated in the lower halves of the layers. Y-on columns were often broader at the tops and the bottoms of the layers than near the centers, giving them an hourglass shape. The Y-off columns were broader at the bottoms of the layers than at the tops, giving them the shape of a cone or a truncated cone.

These distinctive bouton distributions suggest the presence of a sublaminar organization in the A layers based on differences in the density and lateral spread of the terminations of $\mathrm{X}, \mathrm{Y}$-on, and Y-off afferents.
\end{abstract}

Axons in the central nervous system often end in extensive arbors that support hundreds of presynaptic terminals. The spatial forms of the arbors are interesting because their size and shape, and the number and density of their terminals play a role in how afferent information is localized, scaled, and weighted at the axon's target

\footnotetext{
${ }^{1}$ This research was supported by National Institutes of Health Grant EY00568 (to C. R. M.) and Training Grant NS07102-03, and by a Fight for Sight Postdoctoral Research Fellowship. We thank Mrs. Fay Gomes, Mr. Victor Pantani, and Mr. Joseph Wonoski for technical assistance, Drs. William Fletcher and Nina Tumosa for reading the manuscript, and Miss Rae Barolet for typing the manuscript.

${ }^{2}$ To whom correspondence should be sent, at his current address: Departments of Medical Physiology and Anatomy, Health Sciences Center, University of Calgary, Calgary, Alberta, Canada T2N 1N4.
}

site. This paper describes how single, physiologically identified axons from ganglion cells in the cat retina terminate in the dorsal lateral geniculate nucleus (LGNd) of the thalamus. The results reveal previously unknown intralaminar organization in the geniculate by showing that axons with different physiological properties distribute their terminal boutons in distinctive patterns across layers $A$ and $A_{1}$. Initial results from these experiments were reported previously (Bowling and $\mathrm{Mi}$ chael, 1980), and similar experiments have recently been published by Sur and Sherman (1982).

\section{Materials and Methods}

Cats were prepared for the experiments under halothane anesthesia (1 to $2 \%$ ). A tracheotomy was per- 
formed and a femoral vein was cannulated. The lateral rectus muscles of both eyes were cut in order to place hook electrodes around the optic nerves for electrical stimulation. The eyes were treated with atropine $(0.4$ $\mathrm{mg} / \mathrm{ml})$, phenylephrine $(10 \%)$, and proparacaine $(0.5 \%)$ and covered with zero power contact lenses. After placing the animal in a stereotaxic instrument, a trephine hole was made through the skull at a point overlying the geniculate. The eyes were refracted for viewing light stimuli on a tangent screen at a distance of 57 inches. Artificial pupils ( $3 \mathrm{~mm}$ diameter) were placed in front of the eyes. The cats were paralyzed with Flaxedil $(20 \mathrm{mg} /$ hr, i.v., in 5\% dextrose/saline) and artificially respired with nitrous oxide/oxygen $(70 \% / 30 \%)$. Expired $\mathrm{CO}_{2}$, temperature, and the EKG were monitored throughout the experiments.

The glass microelectrodes were filled with potassium acetate $(200 \mathrm{mM})$ and horseradish peroxidase (HRP) (10\%, Sigma type VI) and the tips were broken to diameters of less than $1 \mu \mathrm{m}$ (DC resistance, 200 to 500 megohms). The electrodes were lowered through the brain inside of a guard micropipette (Bowling and Michael, 1980). The guard was filled with saline and positioned just dorsal to the optic tract by recording lightevoked field potentials through it. The electrode was advanced out of the guard in 5- $\mu \mathrm{m}$ steps and the stereotaxic instrument was tapped after each advance. Responses from single fibers were almost never detected extracellularly. Instead, tapping resulted in the sudden impalement of a fiber as evidenced by the appearance of a steady, negative resting potential (10 to $40 \mathrm{mV})$ with positive-going action potentials ( 1 to $10 \mathrm{mV}$ peak). The low resting potentials and small action potentials were probably a result of impaling the fibers with electrode tips that were of the same order of size as the fibers themselves. The fibers could be hyperpolarized and the amplitude of the action potentials increased by passing negative current through the electrodes.

Recordings from single fibers were seldom held for more than 5 to $10 \mathrm{~min}$. During this time the axon's receptive field was located, its sign of response (center on or off) was determined, it was classified as an X or a $\mathrm{Y}$ type (Enroth-Cugell and Robson, 1966), and it was injected with HRP. A number of tests were employed to help distinguish between $\mathrm{X}$ and $\mathrm{Y}$ fibers. We checked for linearity using contrast reversals of a bipartite field (Hamasaki and Sutija, 1979), measured receptive field sizes by mapping the fields with small spots of light (Cleland et al., 1979), judged velocity dependence by moving hand-held stimuli (Stone and Fukuda, 1974), and judged temporal response with step presentations of light or dark stimuli at the centers of the receptive fields (Cleland et al., 1971). However, these tests were not done quantitatively, and their interpretation was sometimes unclear. Uncertainties also arose from limitations of the tests themselves. For example, it is not always possible to demonstrate linearity (i.e., obtain a null response) with a bipartite field because of the low spatial frequency inherent in such a stimulus (Hochstein and Shapley, 1976). Measuring receptive field sizes is also subject to error, especially from one experiment to another, without actually measuring spatial sensitivity. For an easily quantified and reproducible criterion for distinguishing $\mathrm{X}$ and $\mathrm{Y}$ fibers, we measured their conduction latency to stimulation of the optic nerve. When the results of the other tests were inconsistent with one another or in conflict with the results of the latency measurements, we relied on the latency.

Figure 1 is a histogram showing the collected results of latency measurements from 166 fibers from 19 cats. The distribution is bimodal with peaks around 1.5 and $0.7 \mathrm{msec}$. The peaks arise from the $\mathrm{X}$ and $\mathrm{Y}$ fiber groups, respectively (Fukuda, 1971; Cleland et al., 1971), in the retinogeniculate pathway. The solid histograms represent the latencies from the subpopulation of 24 injected fibers which form the main basis of this paper (see below). The latency measurements segregated the 24 fibers into two groups: 15 fast conducting fibers with latencies equal to or less than $0.9 \mathrm{msec}$ (classified as $Y$ type) and 9 slow conducting fibers with latencies greater than $1.0 \mathrm{msec}$ (classified as X type). On average, the latencies of the injected fibers were less than those of the parent population, probably because successfully injected fibers tended to be larger. In the range of latencies between 0.9 and $1.0 \mathrm{msec}$ we did not classify the fibers unless the results of the other tests were clear. The validity of using latency to distinguish between fiber types is supported by the bimodal distribution of the parent population and by the fact that fibers of the two types showed different patterns of central termination (see "Results"). The use of the specific terms $\mathrm{X}$ and $\mathrm{Y}$ for the two groups is consistent with the recognized differences in the conduction velocities of these two kinds of fibers.

After an axon was physiologically characterized, it was injected with HRP by passing positive DC current through the electrode (10 to $50 \mathrm{nA}$ for 10 to $200 \mathrm{sec}$ ).

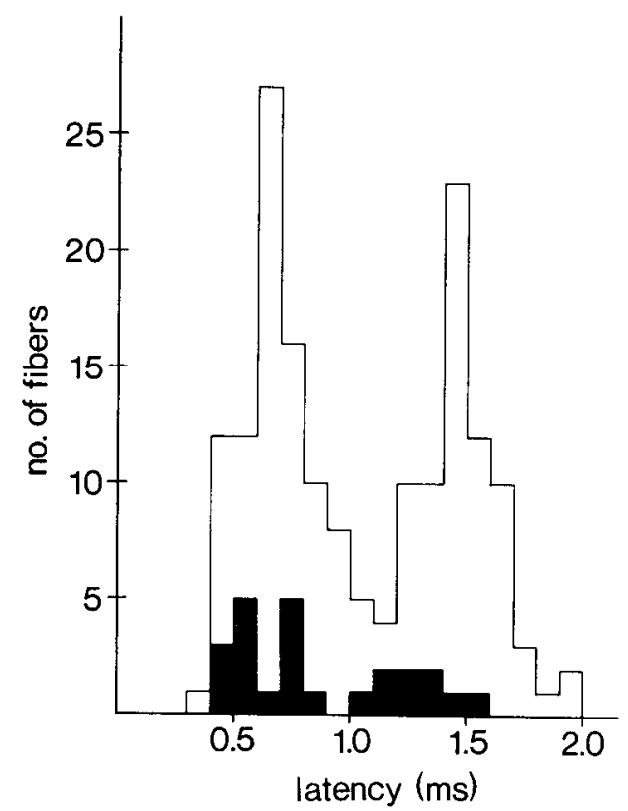

Figure 1. Histograms showing conduction latencies from 166 fibers recorded in the optic tract. The stimulus electrodes were hooked around the optic nerves at the back of the eye. The solid blocks represent the subpopulation of 24 fibers which were successfully injected with HRP and which form the main basis of the results reported in this paper. 
During this time the current was turned off every 5 to $10 \mathrm{sec}$ and the responses of the axon were monitored to assure that it remained impaled. When the recording was lost, the current was stopped and the electrode was withdrawn. To avoid confusion during reconstruction, no more than two or three axons were injected on one side of the brain.

Several hours after the last axon was injected, the cats were given heparin (3000 units, i.v.), deeply anesthetized with thiopental $(30 \mathrm{mg} / \mathrm{kg}$, i.v. $)$, and perfused through the heart (saline rinse followed by $2 \%$ glutaraldehyde, $1 \%$ paraformaldehyde in $100 \mathrm{~mm}$ sodium phosphate buffer, $\mathrm{pH}$ 7.2). The LGNd was removed in a block, allowed to sink in $30 \%$ sucrose, and serially sectioned at $80 \mu \mathrm{m}$ on a freezing stage. The sections were developed for reaction product using diaminobenzidine, cobalt chloride, and nickel ammonium sulfate (Adams, 1981). The fibers were identified in the sections by correlating their injection sites with the stereotaxic coordinates of the microelectrodes.

Sixty individual fibers were impaled, characterized, injected, and recovered histologically, and about half of these (31) were sufficiently well stained to reveal their complete arbors in the laminated portion of the LGNd. Complete staining was confirmed by tracing every branch of an arbor to its ending in one or more terminal boutons. For 24 of the axons the arbors were sectioned nearly orthogonal to the planes of layers $\mathrm{A}$ and $\mathrm{A}_{1}$. The results presented here are mainly from these 24 axons and, with the exception of Figure 1, all of the figures in this paper are based on these fibers. The complete set of 24 fibers is represented in Figures 8 (9 X fibers), 9 ( $7 \mathrm{Y}$-off fibers), 10 (6 Y-on fibers), and 11 ( $2 \mathrm{Y}$ fibers). The rest of the injected fibers (36) were either incompletely stained in the A layers (29) or were reconstructed from less ideal planes of section. However, although incomplete or not analyzed in detail, results from these fibers were consistent with results from the 24 axons represented in the figures. In addition to reconstructions of the fibers' branching patterns, reconstructions were also made of the terminal bouton distributions in the A layers of the LGNd. The distributions were analyzed for their sizes and shapes in the plane of section (usually parasagittal), for their widths orthogonal to the plane of section, and for the uniformity of their bouton densities across the layers. The distributions' widths in the mediolateral dimension (orthogonal to the sections) were obtained by multiplying the section thickness $(80 \mu \mathrm{m})$ by the number of sections or partial sections that contained boutons. All measurements of the widths of the terminal distributions were made by measuring the distance, parallel to the laminar borders, between the most widely spaced terminal boutons. Statistical statements that appear in the text are always given as means $\pm \mathrm{SD}$, and statistical significance is given as a probability level $(p)$ obtained from the Student's $t$ distribution (Campbell, 1974). The terminal distributions of the $\mathrm{Y}$ axons, but not the $\mathrm{X}$ axons, tended to be wider in the anteroposterior dimension than in the mediolateral dimension. This feature was quantified as elliptical eccentricity; i.e., the ratio of the mediolateral width to the anteroposterior width. The uniformity of bouton densities across the layers was measured by counting the numbers of boutons in the upper and lower halves of the layers. The laminar borders were visualized by counterstaining or darkfield microscopy. However, because the planes of section were never exactly orthogonal to the laminar planes, the laminar borders could not be exactly represented in two-dimensional projections. Thus, whereas the reconstructions make it appear that portions of the arbors and terminal boutons sometimes occur outside the laminar borders, this was not the case.

\section{Results}

\section{Responses and injection sites}

The recordings at the top of Figure 2 show the responses of an $\mathrm{X}$ and a $\mathrm{Y}$ fiber to electrical and light stimulation. The stimulus artifacts in the upper traces give the timing of electrical shocks delivered to the optic nerve near the back of the eye. The conduction latencies of the two fibers, measured from the stimulus artifacts to the rising phases of the action potentials, were 1.4 and $0.7 \mathrm{msec}$, respectively. These latencies correspond to conduction velocities of about 21 and $43 \mathrm{msec}^{-1}$ (conduction distance about $3 \mathrm{~cm}$ ) and identify the axons as an $\mathrm{X}$ and a $\mathrm{Y}$ type (Stone and Fukuda, 1974). The responses of the two axons to light are shown directly below the electrically evoked responses. The slower conducting fiber (X) gave a sustained on response to a pulse of light delivered at the center of its receptive field, whereas the rapidly conducting fiber $(\mathrm{Y})$ gave an off response to the light stimulus.

The injection sites of the two axons in Figure 2 are shown in the micrographs to the right of each axon's responses. An injection site from a third axon (Fig. 2, bottom) was cut in cross-section in order to examine it in more detail. The injection site is shown in a photographic montage from an $80-\mu \mathrm{m}$ section in which the axon coursed for some distance. Subsequently, the section was lifted off its microscope slide, imbedded in paraffin, and recut at right angles. Representative crosssections are shown in Figure 2, a to $d$, with arrows indicating their approximate positions. As expected, only one axon profile was filled with reaction product. The cross-sections also reveal that the swollen appearance of the injection site was partly due to stain in the axon's glial sheath. Stained glial processes can be seen surrounding several other label-free axons in Figure $2 c$.

\section{Axon endings}

The fine branches of the axons' arbors invariably ended in one or more synaptic boutons. These spherical or crenulated swellings were usually 2 to $3 \mu \mathrm{m}$ in diameter and were easily resolved in the light microscope (Mason and Robson, 1979). Figure 3 shows drawings of axon branches and terminal boutons from a single section through an X and a Y arbor in the A layers of the LGNd. Full reconstructions of the fibers, based on a number of serial sections, appear in the upper right corner of the figure. The drawings were made with a $\times 100$ oil objective and show the detail that was visible in the $80-\mu \mathrm{m}$ sec- 

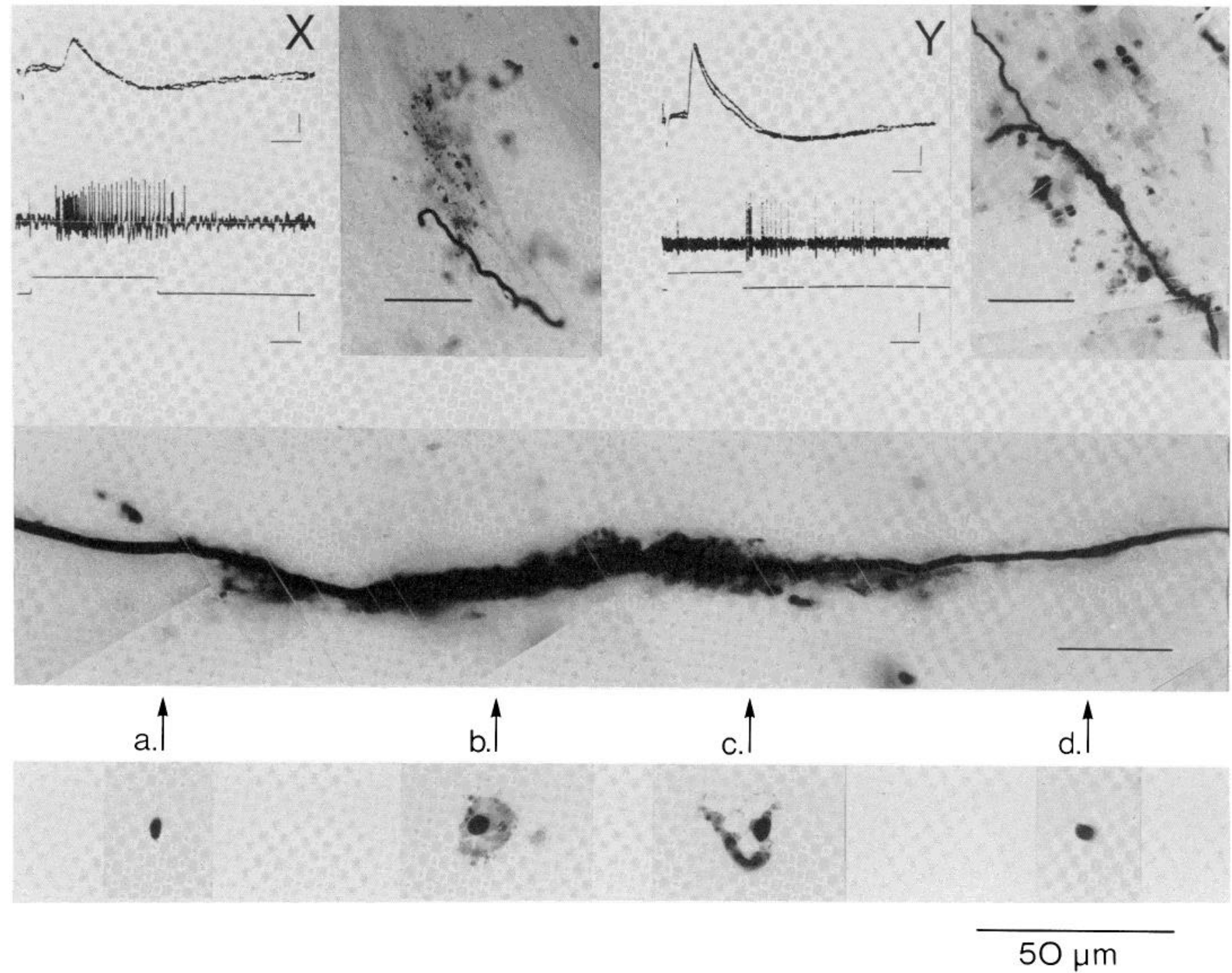

Figure 2. Responses and injection sites of single axons in the optic tract. Top left, Long-latency responses (1.4 msec) of an Xon axon to stimulation of the optic nerve (scale bars, $1 \mathrm{mV}$ and $1 \mathrm{msec}$ ), the axon's sustained response to a pulse of light delivered as a spot within the center of its receptive field (scale bars, $1 \mathrm{mV}$ and $50 \mathrm{msec}$ ), and a photomicrograph of the HRP-stained axon at its injection site. The debris above the axon marks the bottom of the electrode track. Top right, Short-latency response (0.7 $\mathrm{msec}$ ) of a Y-off axon to optic nerve stimulation (scale bars, $1 \mathrm{mV}$ and $1 \mathrm{msec}$ ), the axon's response to a light pulse (scale bars, 1 $\mathrm{mV}$ and $200 \mathrm{msec}$ ), and a photographic montage showing the axon's injection site (near the center of the micrograph). A branch point is located above the injection site. Bottom, Photographic montage of another Y axon at its injection site and four crosssections $(a, b, c$, and $d)$ made by resectioning the axon at right angles. Arrows indicate the approximate locations of the crosssections. Stained glia $(b$ and $c$ ) can be seen surrounding the injected axon as well as adjacent axons $(c)$ that were not injected. Scale bars for all micrographs are $50 \mu \mathrm{m}$.

tions. Note that the blind endings on many branches are cut ends at the surfaces of the section.

Several differences between $\mathrm{X}$ and $\mathrm{Y}$ terminations are illustrated by the drawings in Figure 3, and also by the photomicrographs in Figure 4 which were taken from a second pair of fibers. In general, the arbors of the $\mathrm{X}$ axons were narrower (see below) than the arbors of $\mathrm{Y}$ axons. In addition, the $\mathrm{X}$ boutons tended to be more concentrated and often occurred in small, tight clusters containing several boutons. The Y boutons, on the other hand, never occurred in tight clusters and were not as densely concentrated as $\mathrm{X}$ boutons. The clusters of $\mathrm{X}$ terminals are reminiscent of the grape-like appendages on the dendrites of some geniculate cells (Guillery, 1966; Friedlander et al., 1981), and it has been suggested that they may be presynaptic to the dendritic appendages (Sur and Sherman, 1982).

\section{Axon projection sites}

All of the $\mathrm{X}$ and $\mathrm{Y}$ fibers ( 60 total; $19 \mathrm{X}, 41 \mathrm{Y}$ ) could be traced to terminations in lamina $\mathrm{A}$ or $\mathrm{A}_{1}$ of the lateral geniculate nucleus. The laminar projections most commonly encountered are illustrated by the reconstructions of contralateral fibers in Figure 5 and ipsilateral fibers 


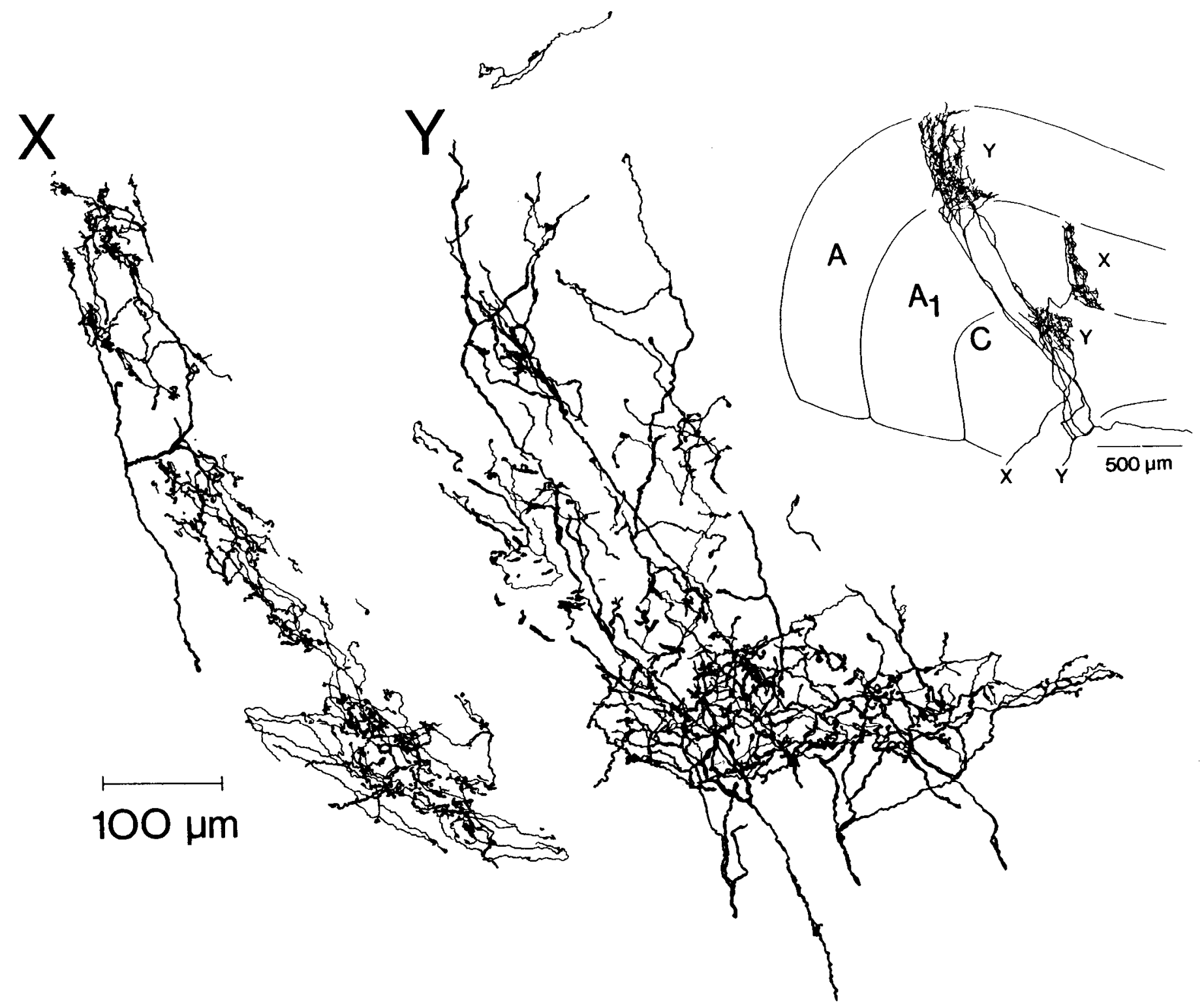

Figure 3. Drawings from a single parasagittal section of two nearby arbors, an X and a $Y$ type, made using a $\times 100$ oil objective. The drawings illustrate the detail that is visible in the sections. They show that $\mathrm{X}$ and $\mathrm{Y}$ axons differ in the size and shape of their arbors and in the density of their terminal boutons. Complete serial reconstructions of the two axons' endings in the geniculate are shown at the upper right.

in Figure 6. The larger drawings show details of the branching patterns and the locations of the injection sites (Figs. 5 and 6, arrows). The smaller drawings show the size, position, and orientation of the axons' arbors in relation to the nucleus and its laminar borders. Contralateral $\mathrm{Y}$ fibers (Fig. 5) usually projected to layer $\mathrm{C}$ as well as layer $A$ ( 27 of 29 ). Thus layers $A$ and $C$ receive most of their $\mathrm{Y}$ input from the same $\mathrm{Y}$ ganglion cells. In contrast, ipsilateral $Y$ fibers (Fig. 6) seldom terminated among the $\mathrm{C}$ layers (i.e., only 2 of 12 terminated in $\mathrm{C}_{1}$ ). The $\mathrm{X}$ axons of Figures 5 and 6 , as with all 19 that were encountered, terminated only in the A layers and sent no projections to the $\mathrm{C}$ layers.

Whereas Figures 5 and 6 illustrate the usual patterns of $\mathrm{Y}$ projections to the laminated portion of the geniculate, two exceptional patterns also occurred. These are illustrated by the examples in Figure 7. On the left is a contralateral $\mathrm{Y}$ fiber that lacked a $\mathrm{C}$ layer termination (2 of 29) and on the right is an ipsilateral $\mathrm{Y}$ fiber that had a termination in layer $C_{1}(2$ of 12$)$.

Some of the $\mathrm{X}$ fibers branched in the optic tract apparently to send a collateral beyond the laminated portion of the LGNd (8 of 19). Five of the collaterals could be traced to terminal boutons in the medial interlaminar nucleus (MIN). However, the endings of the $\mathrm{X}$ fibers in the MIN were never stained well enough to be completely reconstructed. Two X fibers were also traced beyond the MIN on a course toward the pretectum and/ or midbrain.

$\mathrm{Y}$ fibers invariably branched in the optic tract to project beyond the laminated portion of the LGNd (41 of 41). Of the $25 \mathrm{Y}$ axons that were stained well enough 

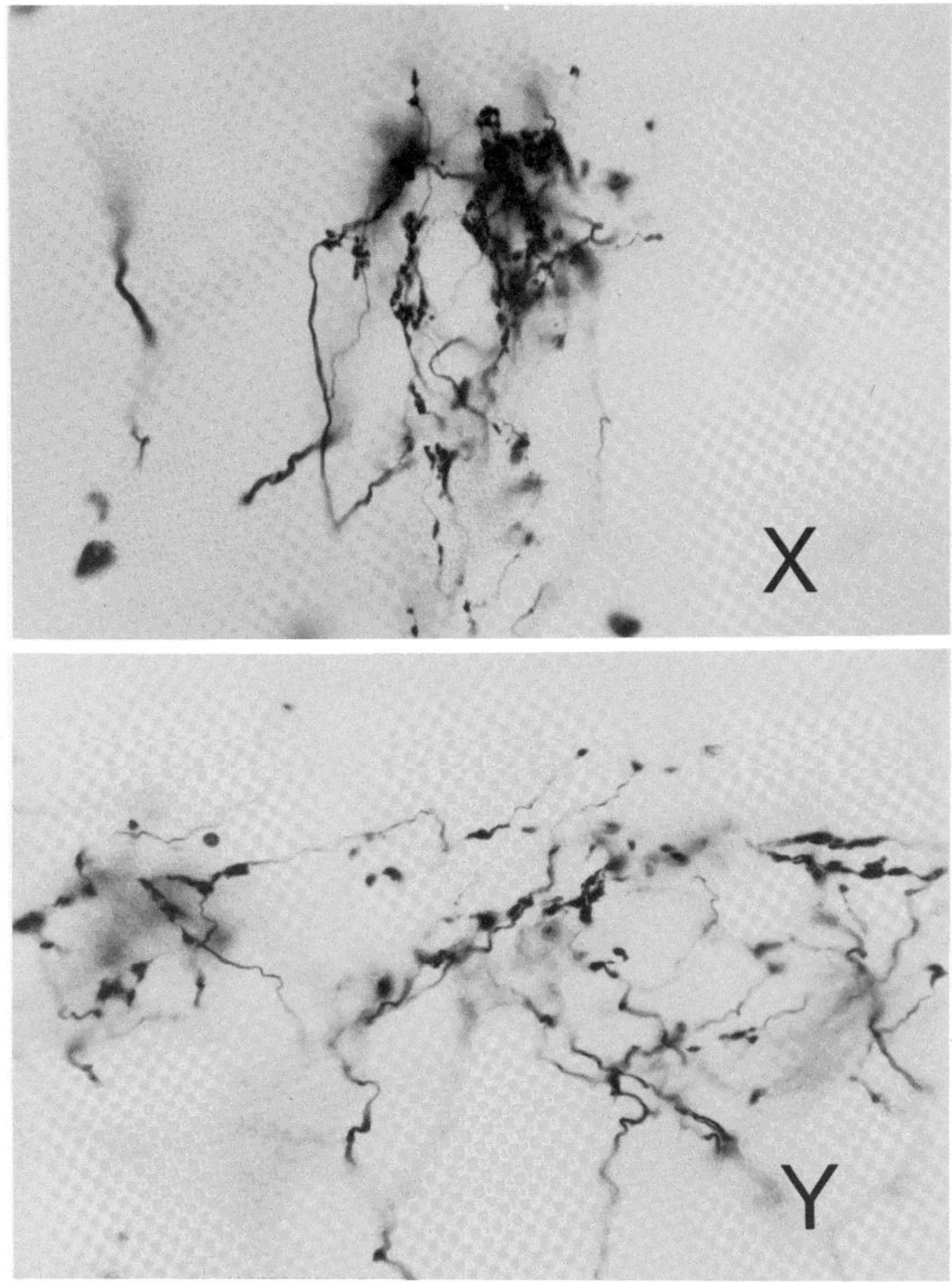

\section{$50 \mu \mathrm{m}$}

Figure 4. Photomicrographs of $80-\mu \mathrm{m}$-thick sections showing terminal boutons of $\mathrm{X}$ and $\mathrm{Y}$ axons in the A layers of the lateral geniculate nucleus. The spread of the $\mathrm{X}$ boutons is narrower than that of the $\mathrm{Y}$ boutons. The $\mathrm{X}$ boutons are more densely packed and tend to occur in clusters. Both micrographs are from the densest parts of the axons' arbor: near the top of the layer for the X axon and near the bottom of the layer for the Y axon. 


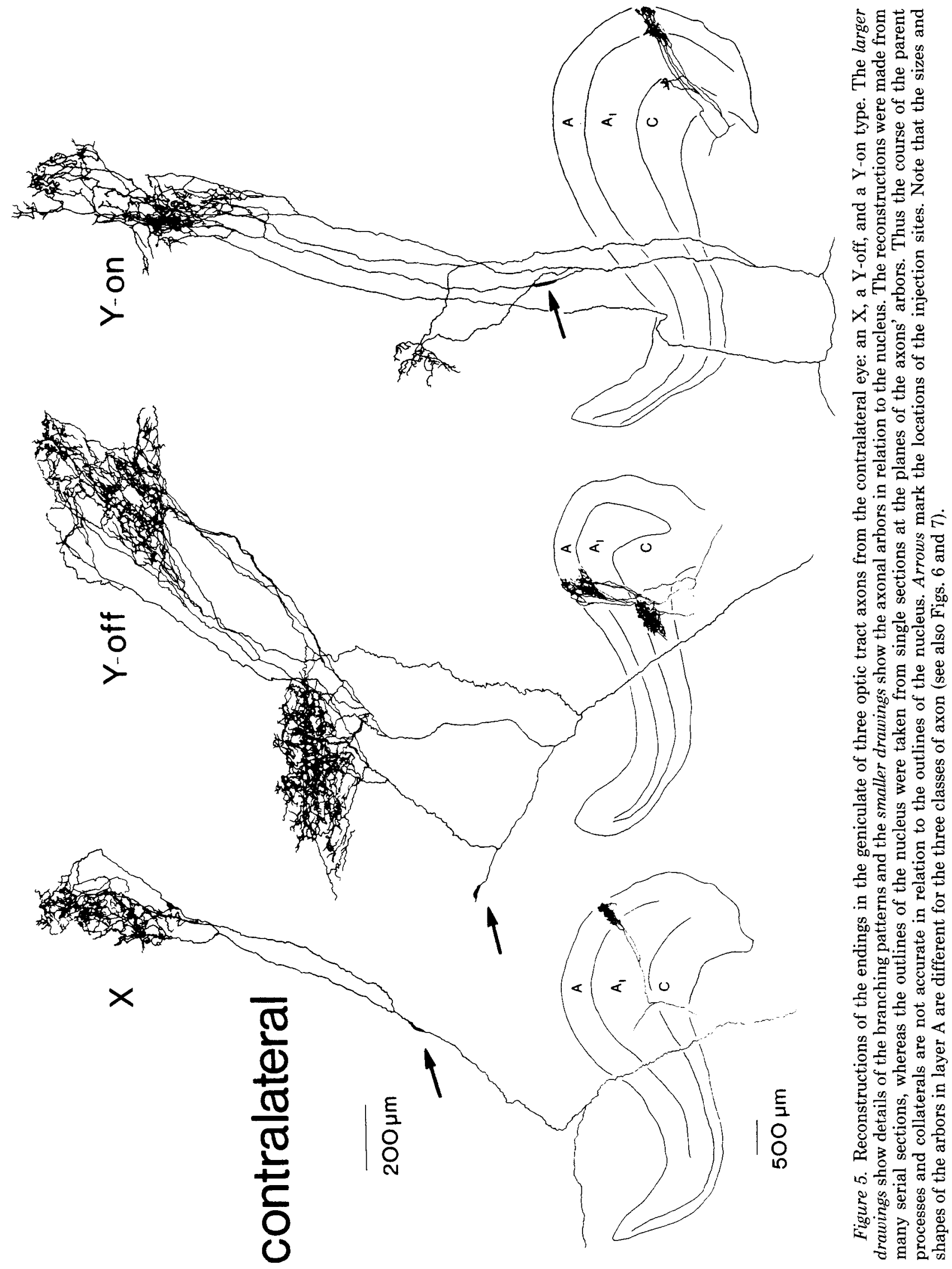



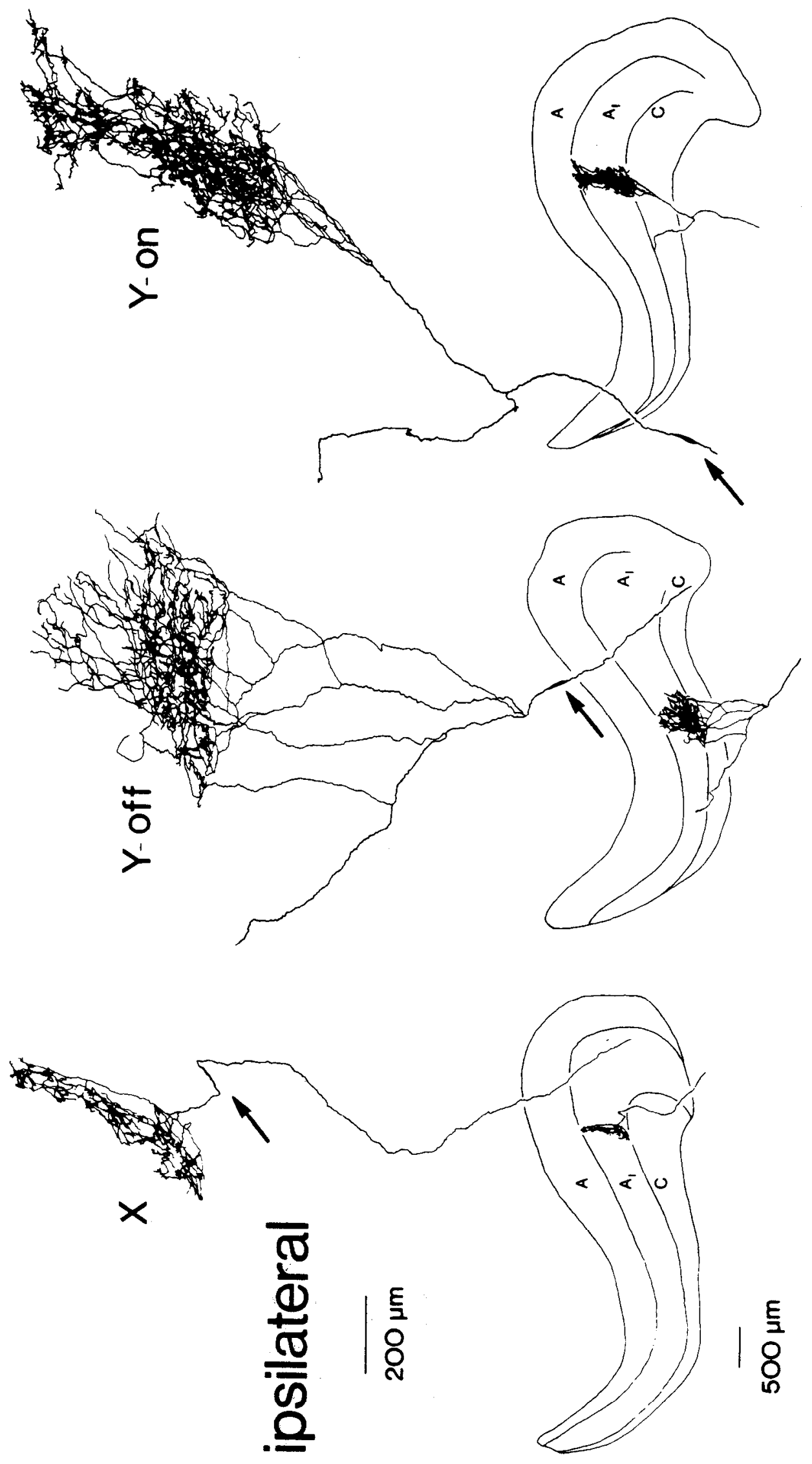

幽

$\Xi$

20

苛

焉.

a

옹 

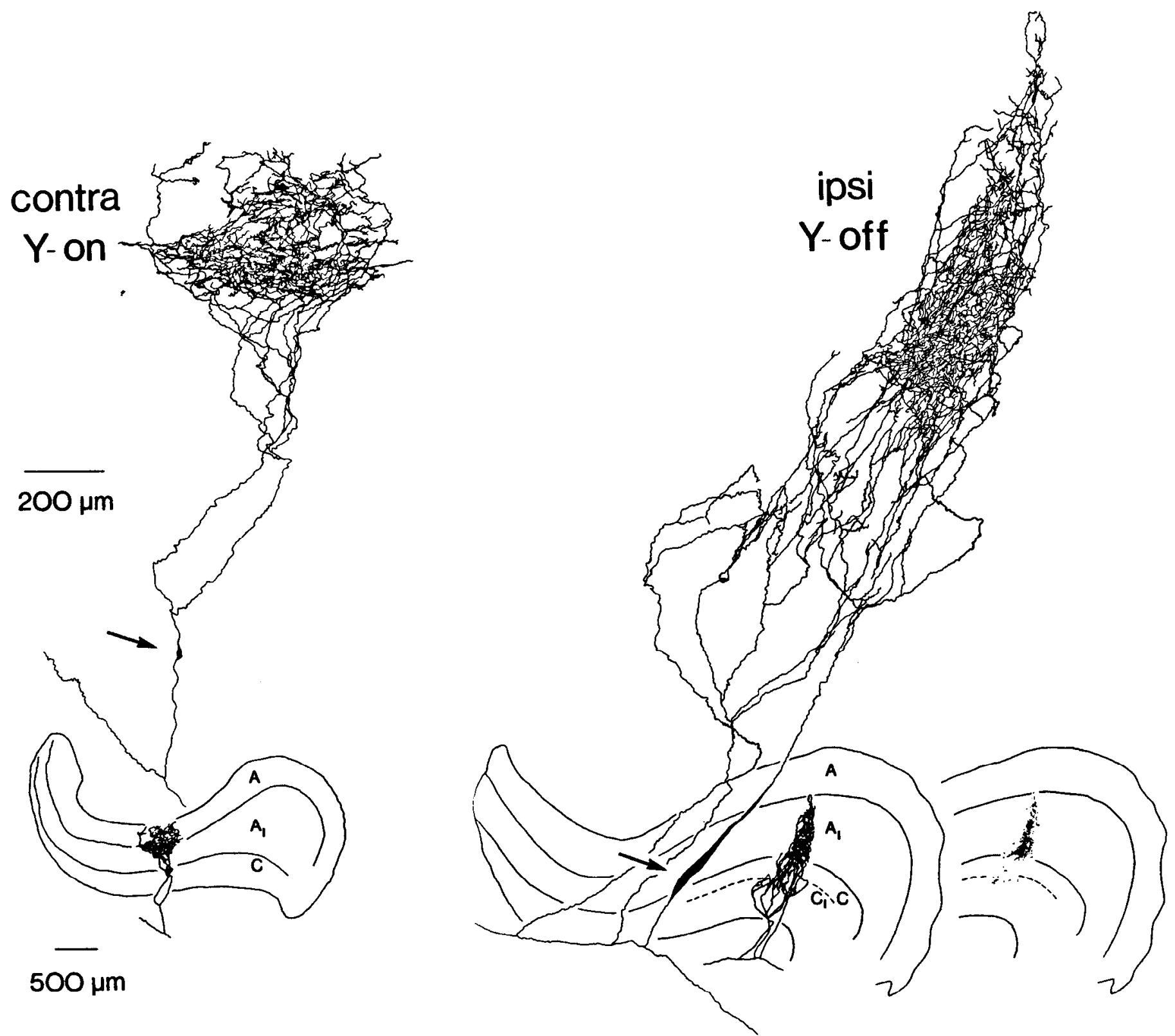

Figure 7. Two atypical patterns of projection of Y axons to the lateral geniculate nucleus. Left, A contralateral Y axon without a C lamina ending. Right, An ipsilateral $\mathrm{Y}$ axon with terminations in lamina $\mathrm{C}_{1}$. Although the patterns of projection were not the same as for most $Y$ axons, the spatial forms of the arbors in layers $A$ and $A_{1}$ were similar; i.e., hourglass shaped for the $Y$-on fiber and conical for the Y-off fiber.

to judge, all projected into the MIN and all had a collateral that went beyond the MIN toward the pretectum and/or midbrain. Several of the Y fibers (four) could be traced to terminal boutons in the superior colliculus, but their arbors were not completely filled there. An earlier report that described the termination pattern of a $\mathrm{Y}$ axon in the colliculus (Bowling and Michael, 1980) was partly in error since only some of the terminal boutons were actually in the colliculus while the rest were in the pretectum.

\section{Distributions of terminal boutons in the A layers}

Axon arbors from fibers of different physiological types appeared to have different shapes in layers $A$ and $A_{1}$. This can be seen in the arbors illustrated in Figures 5 to
7. The $X$ arbors were narrow and of nearly uniform width across the layers. The $\mathrm{Y}$ arbors were broader but not of constant width. It also appeared that $\mathrm{Y}$-off arbors were wider at the bottoms of the layers than at the tops. In contrast, the $\mathrm{Y}$-on arbors appeared broad at both the tops and bottoms of the layers but were narrower and less profuse near the centers.

The shapes of the arbors may partly reflect their developmental histories, as well as the spatial patterns of their connections. Therefore, it may be more important from a functional point of view to examine the actual distributions of the fibers' terminal boutons. Figures 8 to 10 show the distributions of terminal boutons in the A layers from 22 fibers (9 X, 7 Y-off, $6 \mathrm{Y}$-on). The figures have two rows of reconstructions: the upper rows 


\section{$X$ on \& off}
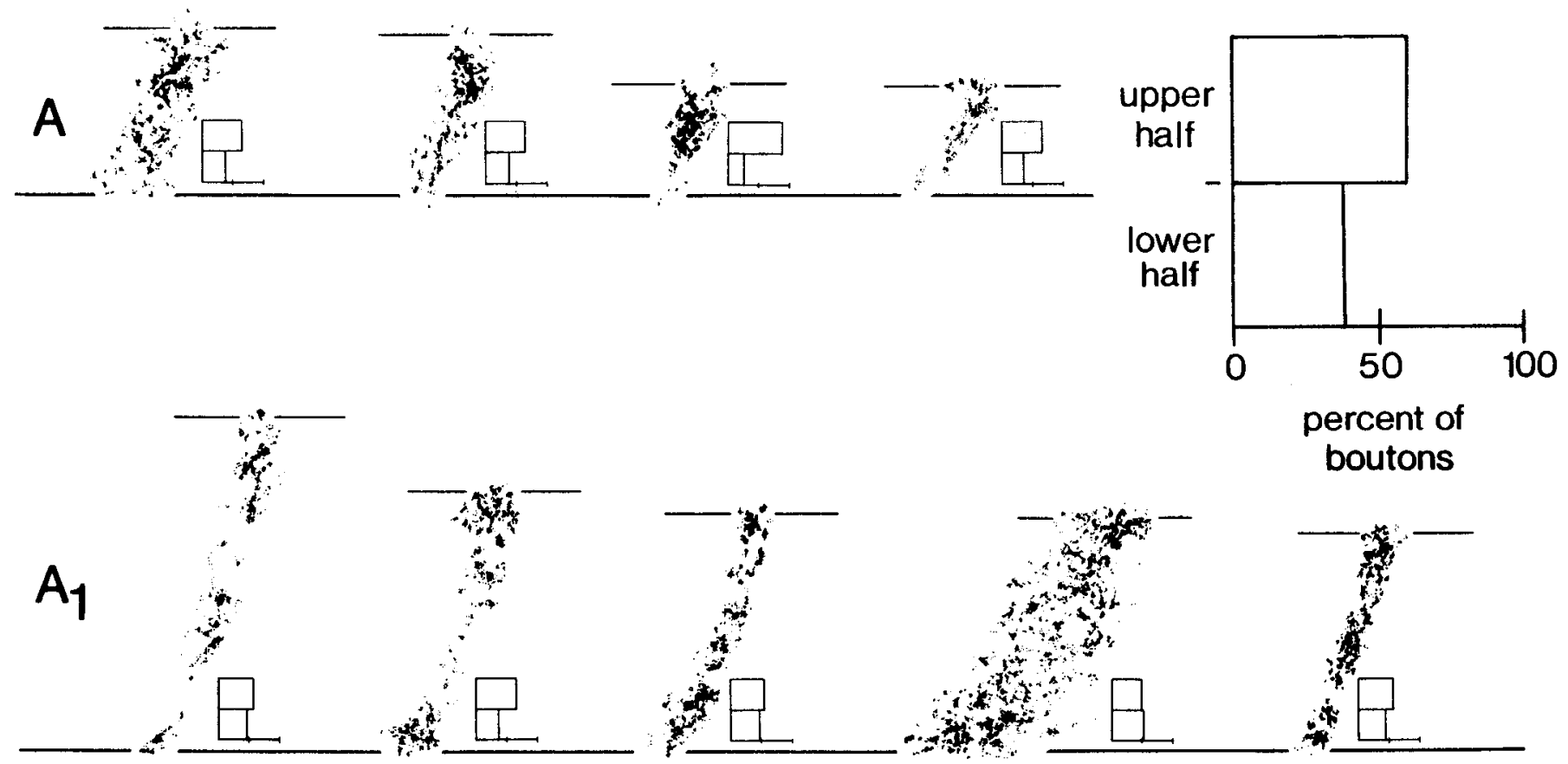

$200 \mu \mathrm{m}$

Figure 8. Reconstructions of the terminal distributions of X axons in the A layers of the LGNd. The distributions in the upper row are from contralateral axons (lamina A) and those in the lower row are from ipsilateral axons (lamina $\mathrm{A}_{1}$ ). Each $\mathrm{dot}_{\mathrm{fepresents}}$ a single terminal bouton. The horizontal lines show the approximate locations of the laminar borders. All of the reconstructions are from parasagittal sections. The shapes of the distributions are basically narrow cylindrical columns. There is a tendency for more boutons to occur in the upper halves of the columns than in the lower halves. This differential distribution is represented for each column by a small histogram and for the whole set of columns, by the averaged histogram (upper right). The eccentricities of the axons' receptive fields in the visual field were, from left to right, starting at the top: $21^{\circ}, 22^{\circ}, 13^{\circ}, 39^{\circ}, 14^{\circ}, 1^{\circ}, 17^{\circ}, 13^{\circ}$, and $22^{\circ}$. Similarly, their latencies in milliseconds were $1.2,1.6,1.2,1.5,1.4,1.1,1.3,1.3$, and 1.4.

show columns of boutons from contralateral axons that ended in layer $\mathrm{A}$ and the lower rows show columns of boutons from ipsilateral axons that ended in layer $A_{1}$. The figure legends give the eccentricities of the axons' receptive fields in the visual field and the axons' conduction latencies.

The three figures illustrate that all of the terminal columns spanned the entire widths of the A layers. However, the sizes, shapes, and densities of the columns appeared to vary depending on their physiological type. The $\mathrm{X}$ columns shown in Figure 8 are generally narrow (146 $\mu \mathrm{m} \pm 78 \mu \mathrm{m}$, mean $\pm \mathrm{SD}, n=9)$ and cylindrical in shape. The Y columns in Figures 9 and 10 are clearly wider $(374 \mu \mathrm{m} \pm 131 \mu \mathrm{m}, n=13)$ but their shapes are more variable. The difference in widths between the $\mathrm{X}$ and $\mathrm{Y}$ columns is statistically significant $(p<0.005)$. A comparison of the shapes of the Y-off columns (Fig. 9) and the Y-on columns (Fig. 10) indicates that, like the arbors that give rise to them (e.g., Figs. 5 to 7 ), there is a tendency for a difference in shape between the two groups. The Y-off columns in Figure 9 are generally narrower at the tops of the layers than at the bottoms.
The ratio of top to bottom widths is $0.49 \pm 0.21(n=7)$. The Y-on columns (Fig. 10), on the other hand, are about equally wide at the tops and bottoms with a ratio of top to bottom widths of $0.97 \pm 0.28(n=6)$. The difference between the ratios for the two types of $Y$ columns is statistically significant $(p<0.005)$. Thus the Y-off columns of boutons can be described as having a conical or truncated cone shape. In contrast, the Y-on columns do not become narrower at the tops of the layers. In fact, the results in Figure 10 suggest that the Y-on columns are often narrower near the centers of the layers and are shaped more like an hourglass than a cone.

It was clear in reconstructing the columns from serial sections that the $\mathrm{Y}$ terminals were spread more broadly along the anteroposterior axis of the geniculate than along the mediolateral axis. Thus the $\mathrm{Y}$ columns appeared to be elliptical in the plane of the retinotopic map with their longer axes oriented along lines of changing elevation in the visual field. This was not so for the $\mathrm{X}$ columns which appeared to be circularly symmetric in the plane of the map. The elliptical eccentricity (ratio of mediolateral width to anteroposterior width; see "Mate- 

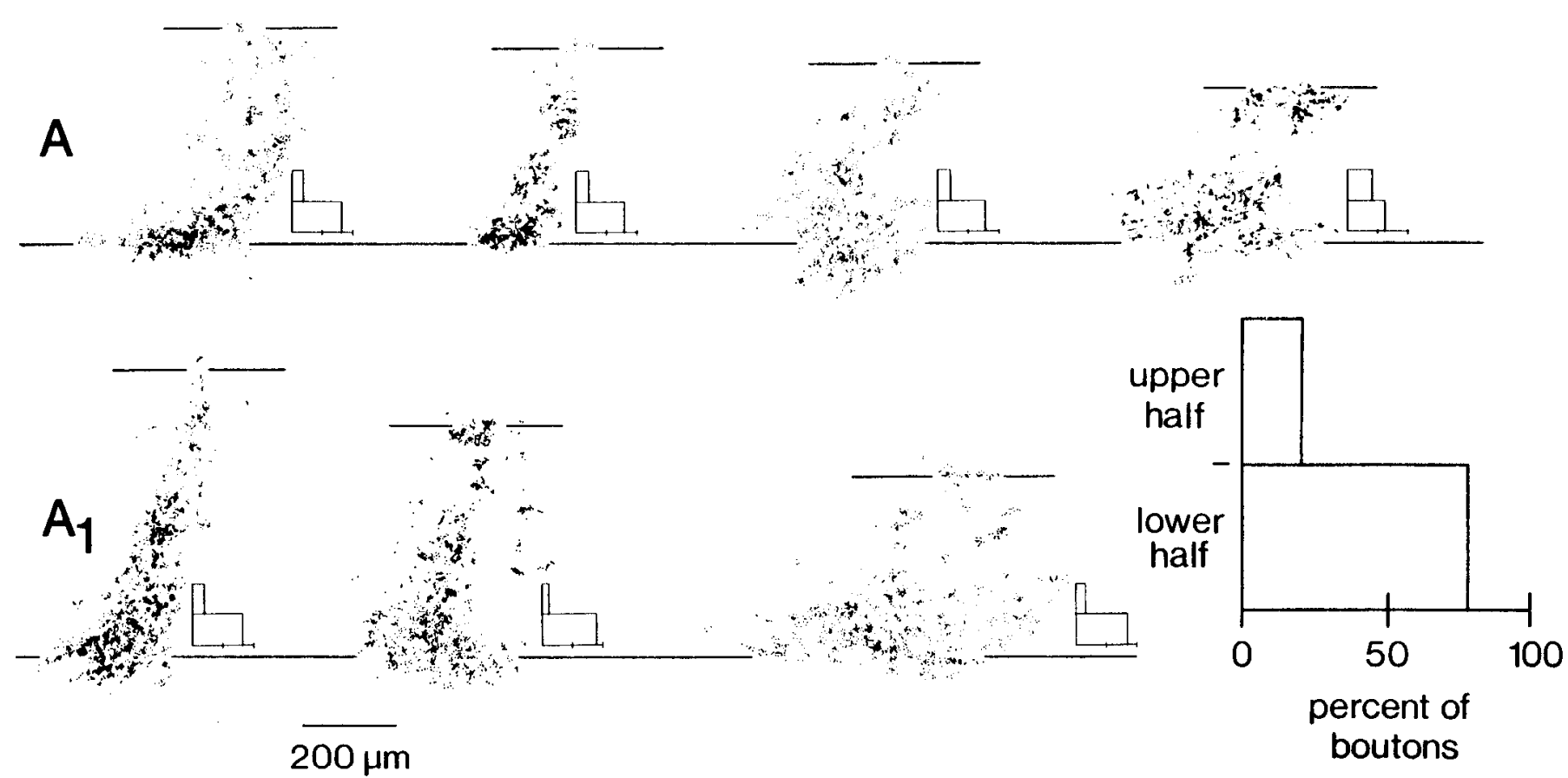

Figure 9. Reconstructions of the terminal distributions of $\mathrm{Y}$-off axons in the A layers of the LGNd. All of the reconstructions are from parasagittal sections except the third from the left in the top row and the second from the left in the bottom row, which are from frontal sections. The distributions form columns that tend to be broader at their bases than at the tops of the layers. The histograms show that the axons' terminal boutons are found in greater numbers in the lower halves of the columns. The ratios of mediolateral to anteroposterior widths of the columns are, from left to right, starting at the top: $0.7,1.1,0.1,0.8,0.9$, 0.7 , and 0.4 . The eccentricities of the axons' receptive fields in the visual field were about $15^{\circ}, 28^{\circ}, 36^{\circ}, 16^{\circ}, 12^{\circ}, 9^{\circ}$, and $25^{\circ}$. Their latencies in milliseconds were $0.8,0.9,0.6,0.8,0.5,0.5$, and 0.6 .

\section{Y-on}
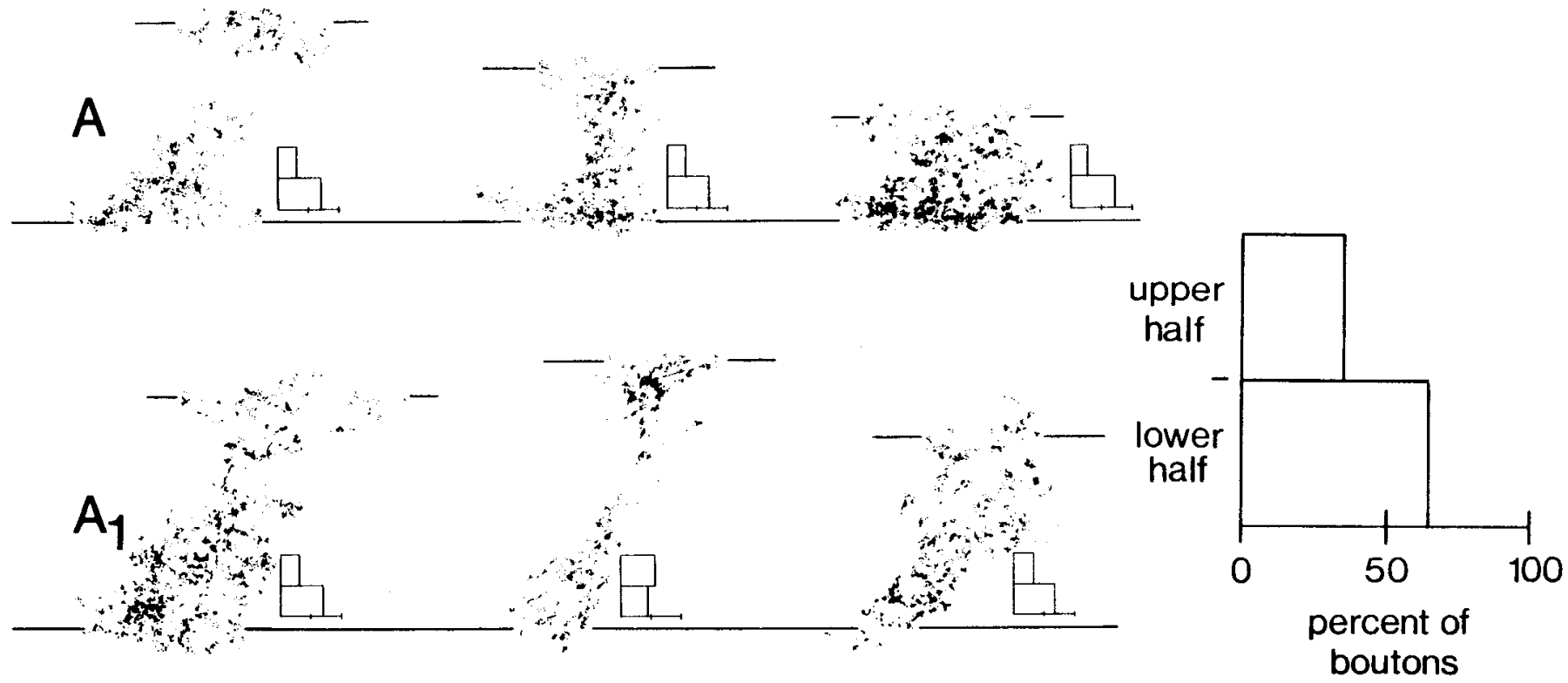

\section{$200 \mu \mathrm{m}$}

Figure 10. Reconstruction of the terminal distributions of Y-on axons in the A layers of the LGNd. All of the reconstructions are from parasagittal sections. The distributions form columns that tend to be narrower near the centers of the layer than at the tops or the bottoms, where they are about equally broad. The histograms show that more boutons occur in the lower halves of the columns than in the upper halves. The ratios of mediolateral to anteroposterior widths of the columns are, from left to right, starting at the top: $0.8,0.6,0.4,0.7,1.0$, and 0.7 . The eccentricities of the axons' receptive fields in the visual field were about $41^{\circ}, 1^{\circ}, 24^{\circ}, 12^{\circ}, 17^{\circ}$, and $11^{\circ}$. Their latencies in milliseconds were: $0.6,0.6,0.8,0.6,0.5$, and 0.7 . 
rials and Methods") of each of the Y columns in Figures 9 and 10 is given in the figure legends. For the 13 fibers represented in the figures the average elliptical eccentricity was about $0.7(0.707 \pm 0.22)$.

Besides differences in size and shape, the $\mathrm{X}$ and $\mathrm{Y}$ terminal distributions were also different in the densities of their boutons across the A layers. The small histograms next to each of the distributions in Figures 8, 9, and 10 represent the percentage of the boutons in the upper and lower halves of the terminal columns. The large histograms show the averages for the entire set of distributions in each figure. For the $\mathrm{X}$ axons of the Figure $8,61 \pm 12 \%(n=9)$ of the boutons were in the upper halves of the columns. In contrast, terminals from $\mathrm{Y}$ fibers were more abundant in the lower halves of the columns. For the $\mathrm{Y}$ axons of Figures 9 and 10, $79 \pm 9 \%$ $(n=7)$ of the Y-off boutons and $65 \pm 10 \%(n=6)$ of the Y-on boutons were in the lower halves of the layers. Averaging the on and off types, about $73 \pm 12 \%(n=13)$ of the $\mathrm{Y}$ boutons were in the lower halves of the layers. The percentage differences in bouton distributions of the $\mathrm{X}$ and $\mathrm{Y}$ fibers between the upper and lower halves of the layers are statistically significant $(p<0.025)$, and the percentage differences between the $\mathrm{Y}$-on and the $\mathrm{Y}$ off distributions are also significant $(p<0.025)$.

\section{A pair of fibers with nearby receptive fields}

Occasionally, fibers were injected that had receptive fields close to one another in the visual field. In one instance a pair of such fibers were from the same eye (contralateral), were completely stained in layer A, and were sectioned nearly orthogonal to the plane of the layer. These results provided an opportunity to determine directly the local magnification factor at the site of the fibers' endings. This allowed the angular sizes of the axons' terminal fields to be measured and compared with the angular sizes of their receptive field centers measured physiologically. Furthermore, as described under "Discussion," the results allow an estimate of the overlap between terminal fields from $\mathrm{Y}$ fibers that represent adjacent points in the visual field.

Figure 11 (upper left) shows the responses of the two axons, a Y-on and a Y-off type, and the nearby locations of their receptive fields. The dashed lines represent the vertical and the horizontal meridians. The distance in the visual field between the centers of the receptive fields was $3.1^{\circ}$. Separate reconstructions of the fibers are shown at the lower left. The combined reconstruction of both fibers' arbors in layers A and C is shown on a larger scale at the lower right. Although the arbors seem entwined, they could be distinguished during reconstruction because they seldom crossed one another in the same sections.

At the upper right of Figure 11 is a representation of the axons' terminal columns viewed from above, looking down on the retinotopic map in the plane of layer $\mathrm{A}$. The representation is based on separate measurements of the extent of the terminal distributions in each serial section. The view illustrates the elliptical nature of the Y terminal columns in cross-section. The magnification factor $(\mathrm{m})$ at the site of the axons' arbors $\left(6^{\circ}\right.$ eccentricity) was taken as the ratio of the distance between the centers of the distributions $(408 \mu \mathrm{m})$ to the angular separation of the receptive fields $\left(3.1^{\circ}\right)$. This gives a value for $m$ of about $130 \mu$ /degree $\left(408 \mu \mathrm{m} / 3.1^{\circ}\right)$.

The angular sizes of the terminal distributions in the plane of the retinotopic map were roughly $2^{\circ} \times 4^{\circ}(300$ $\times 550 \mu \mathrm{m})$ for the $\mathrm{Y}$-on fiber and $3^{\circ} \times 6^{\circ}(400 \times 800 \mu \mathrm{m})$ for the Y-off fiber. This is interesting because the maps of the fibers' receptive fields measured physiologically (Fig. 11, upper left), and previous measurements of $\mathrm{Y}$ ganglion cell receptive fields at $6^{\circ}$ eccentricity (Cleland et al., 1979) indicate that the angular sizes of the field centers are only about $1^{\circ}$ and $1.5^{\circ}$. Thus the columns covered greater angular widths in the retinotopic map than did the centers of the fiber's receptive fields in the visual field. This is consistent with the idea that many of the terminal boutons contribute to lateral interactions rather than to direct excitation of principal cells.

\section{Terminal distribulions of $Y$ axons in the MIN}

The $\mathrm{Y}$ axons sent one or more collaterals into the medial interlaminar nucleus ( 25 of 25 ), and eight of the axon endings were completely stained there. Figure 12 shows the arbors and terminal distributions in the MIN from four of the $\mathrm{Y}$ axons: two contralateral and two ipsilateral. For each eye of origin, both a parasagittal and a frontal reconstruction are represented. From the perspective of the frontal reconstructions the distributions of boutons were about $150 \mu \mathrm{m}$ wide, whereas from the sagittal perspective they were between 200 and $500 \mu \mathrm{m}$ wide. Thus, like the $\mathrm{Y}$ terminal distributions in layers $\mathrm{A}$ and $A_{1}$, the distributions in the MIN were elongated in the anteroposterior direction.

Terminals from the contralateral fibers ending in the MIN sometimes gave the appearance of being distributed in two separate groups. 'This point is particularly obvious for the contralateral fiber that was reconstructed from frontal sections. It is not as clear for the contralateral fiber that was cut parasagittally, partly because the plane of section was less ideal. Since an ipsilateral and a contralateral fiber were never filled in the same MIN, it is not known how the patterns of terminations of the two types relate to one another. A more complete description of the geometry of the terminations in the MIN will require a larger sample and a more detailed three-dimensional analysis.

\section{Transneuronal labeling}

Cell bodies lightly labeled with HRP were seen within about half of the completely stained arbors in the A layers (14 of 31). The intensity of the labeling varied from barely detectable to quite obvious (see Fig. 13). The number of visibly labeled cells was also variable (1 to 15 ) and appeared to depend partly on the density of stain in the axon. A similar phenomenon of transneuronal labeling following intra-axonal injection of HRP has also been reported by Hongo et al. (1981), Triller and Korn (1981), and Baker and Grantyn (1982).

When the proximal dendrites of the labeled cells were visible, they often appeared to be contacted by one or more of the axons' terminal boutons. Figure 13 shows 


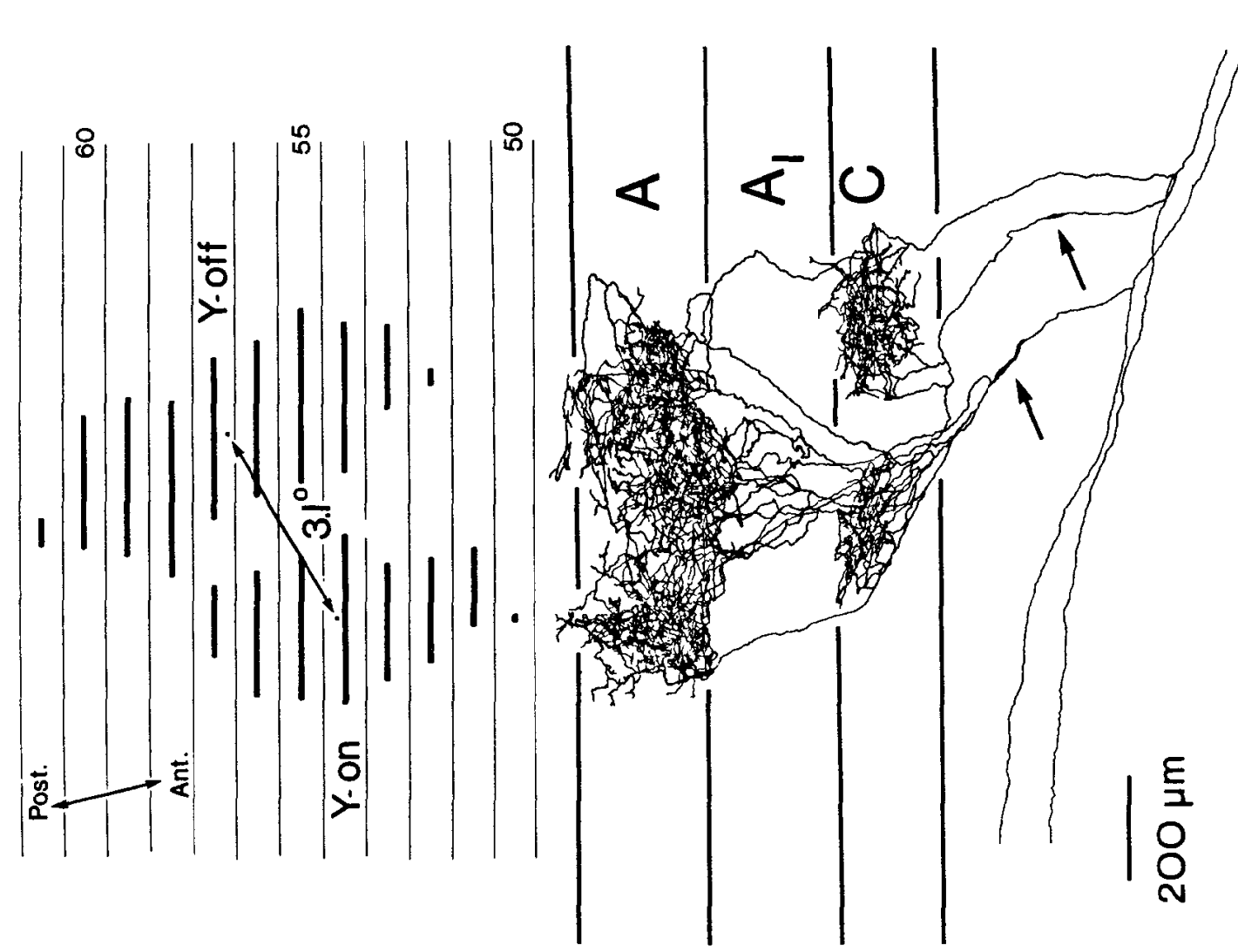

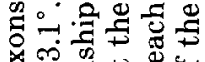
के कू

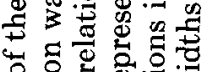

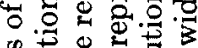
率需要

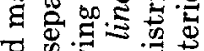

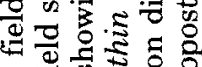

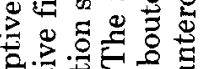
पे क्ष

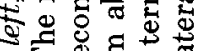
此要 क : .7융

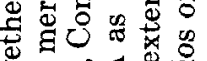

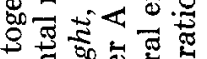
\% ن

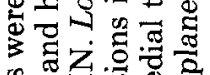

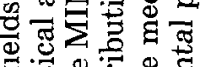

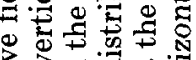

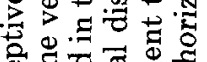

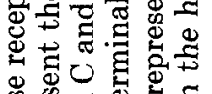

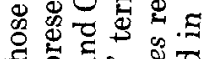

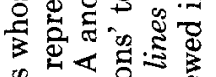
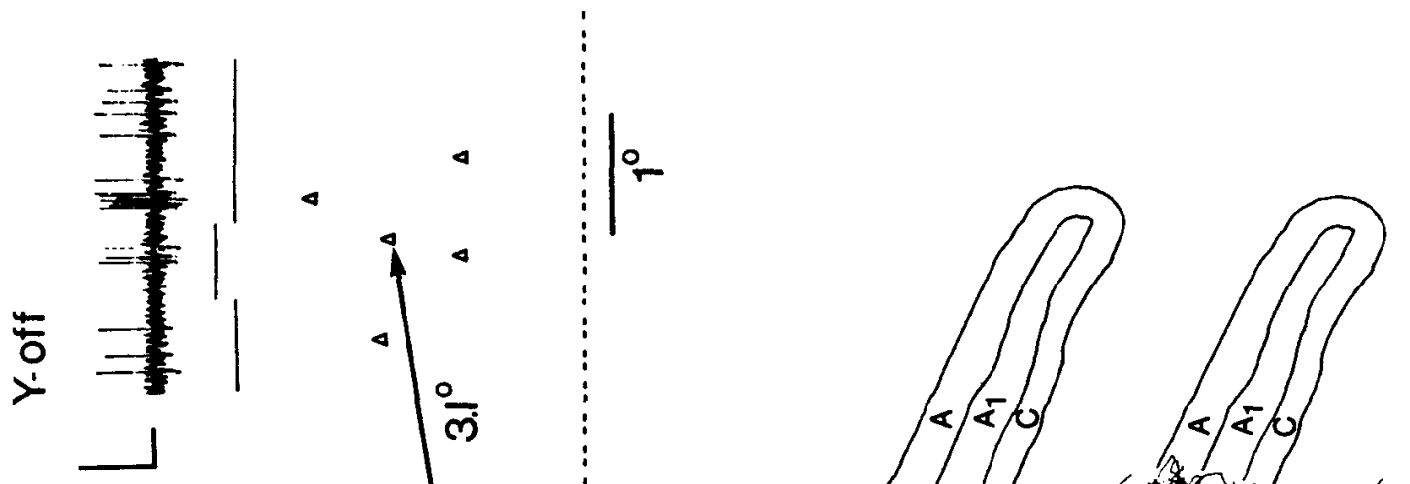

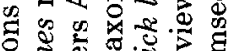

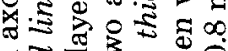
匹

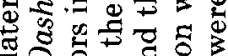

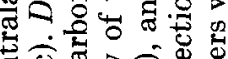

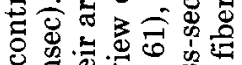
$\circ$ 过 5 :

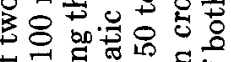

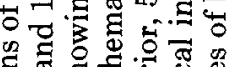

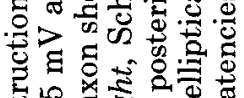

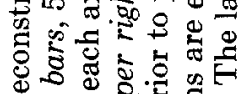
क्ष $3 / 4$ 放

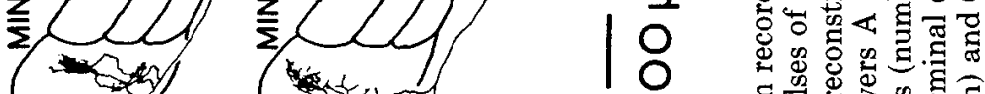

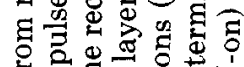

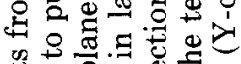
की

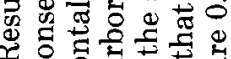

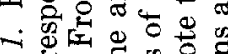

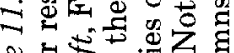

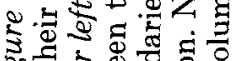

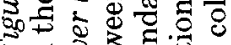




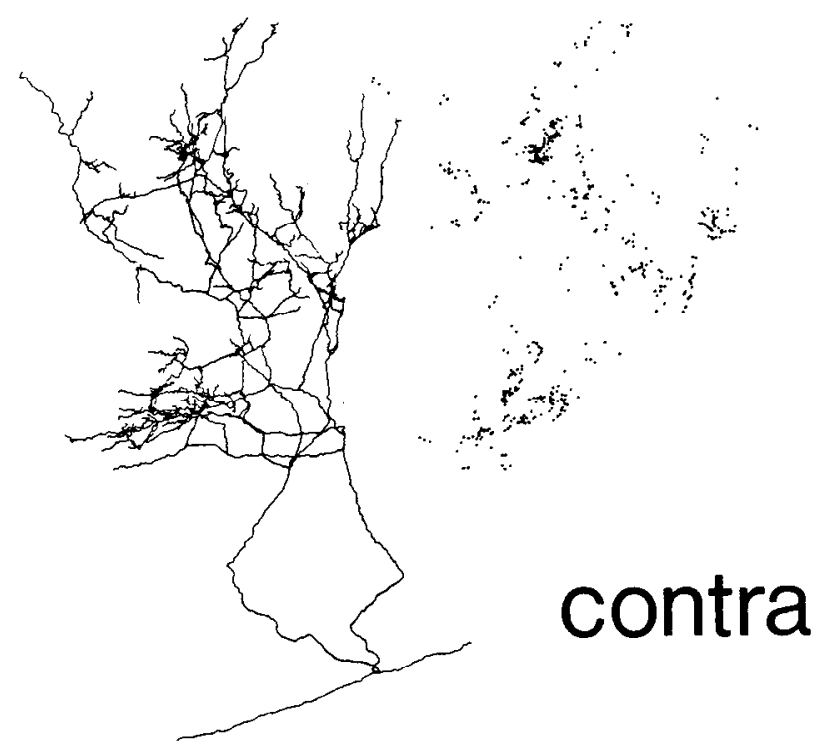

parasagittal

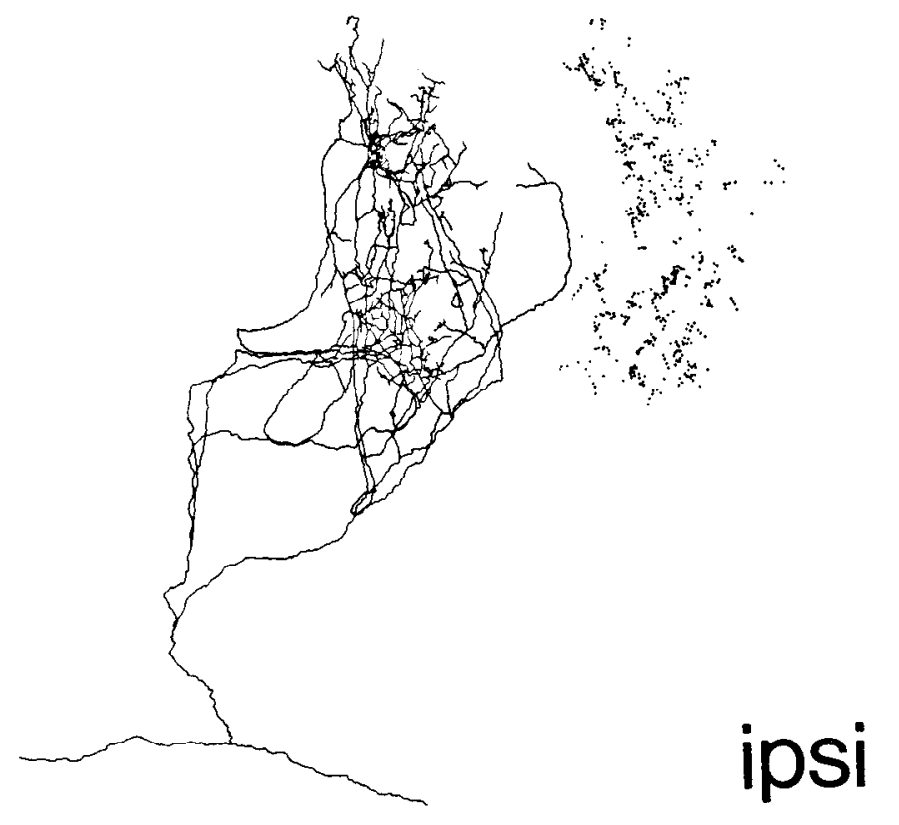

parasagittal

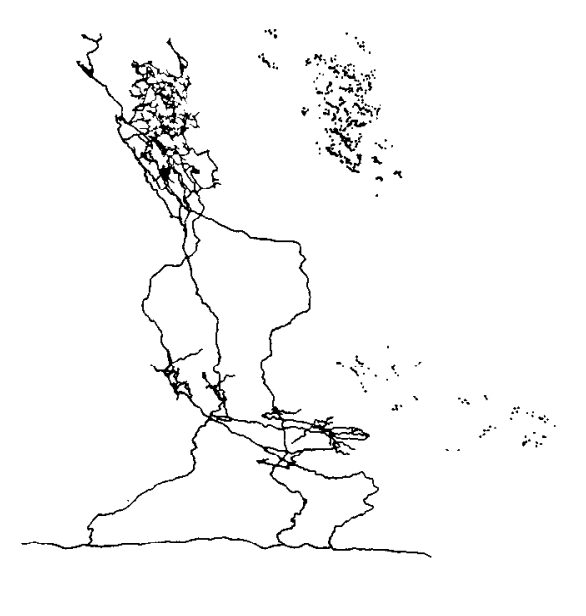

frontal

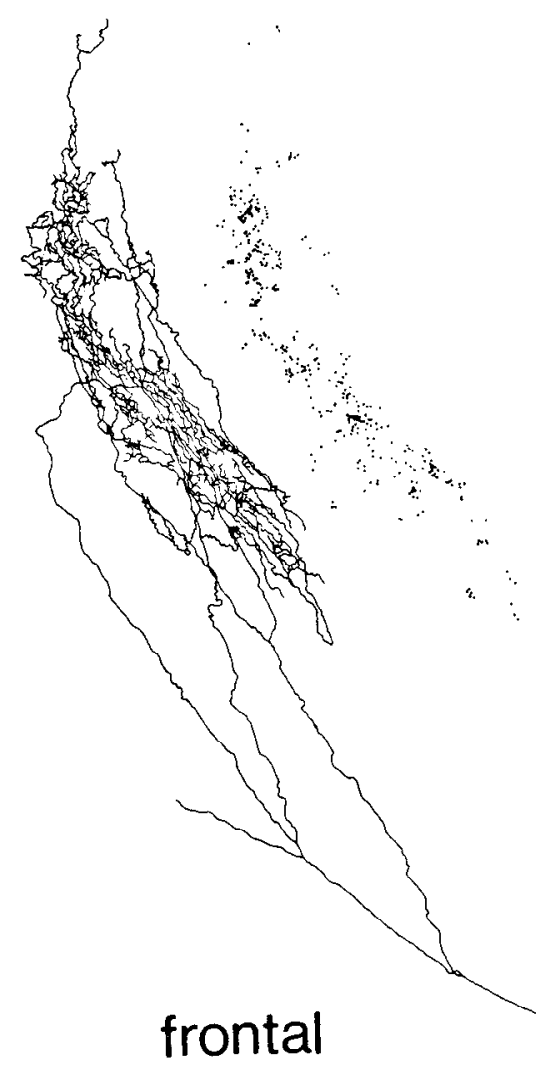

$200 \mu \mathrm{m}$

Figure 12. Parasagittal and frontal reconstructions of the arbors and bouton distributions of four Y axons in the MIN. The bouton distributions were narrower in the frontal plane than they were in the parasagittal plane. 


\section{$\mathrm{X}$}

Y

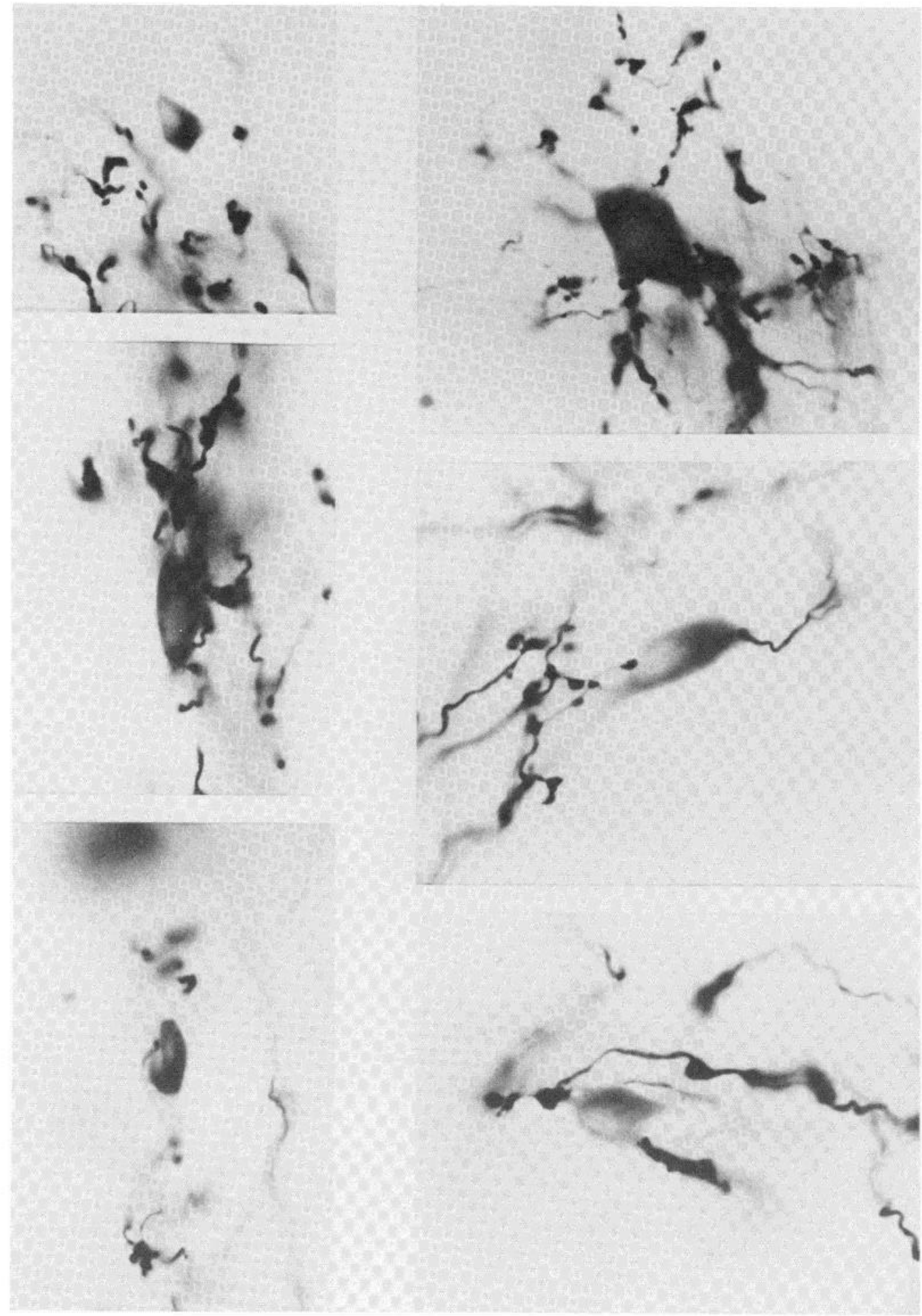

\section{$50 \mu \mathrm{m}$}

Figure 13. Photomicrographs of cells stained transneuronally by single injected axons. The four cells on the left (there are two closely apposed in the bottom frame) were all labeled by a single ipsilateral $\mathrm{X}$ axon. A total of eight cells were stained (see reconstruction in Fig. 14). The three cells on the right were labeled by three different $\mathrm{Y}$ axons and are, from top to bottom: in lamina $\mathrm{A}_{1}$, lamina $\mathrm{C}$, and the MIN. 
examples of labeled cells surrounded by darkly stained axon processes. The four cells on the left of the figure were labeled in layer $\mathrm{A}$ from the injection of an ipsilateral $\mathrm{X}$ axon. The cells on the right of Figure 13 were labeled from three different $\mathrm{Y}$ axons and were located, from top to bottom, in lamina $A_{1}$, lamina $C$, and the MIN.

Figure 14 shows reconstructions of the terminal distributions and labeled cells from the injection of an $\mathrm{X}$ and a Y fiber. The boutons not visibly in contact with any cell are represented by dots, and those that appeared to be in contact with dendritic processes are drawn as solid black figures. The reconstructions were made using a $\times 100$ oil objective. It is not known whether the transneuronal labeling is specific for cells that are postsynaptic to the injected fibers. It is possible that some neurons may simply take up enzyme which leaks from axon terminals, independent of whether the cells are synaptically contacted by them. However, the results in Figure 14 are consistent with a specific or trans-synaptic mechanism of labeling. As a group, the cells labeled by the $\mathrm{X}$ fiber are smaller than the cells labeled by the $\mathrm{Y}$ fiber. They have spindle-shaped somas with vertically oriented dendrites, and none appeared to be Guillery class I cells which have been shown to be Y type (Friedlander et al., 1981). In contrast, the cells stained by the injection of the $\mathrm{Y}$ fiber were larger, more variable in shape, and included at least one very large cell with radially symmetric dendrites (probably Guillery class I). Friedlander et al. (1981) observed similar differences between X and Y cells when they injected them directly with HRP. Still, the phenomenon is highly variable both in the density and in the numbers of labeled cells, and the mechanism and specificity of the labeling are unknown. Thus it is not yet possible to interpret the results with certainty.

\section{Discussion}

The projection sites of the $\mathrm{X}$ and $\mathrm{Y}$ axons were largely consistent with the known locations of $\mathrm{X}$ and $\mathrm{Y}$ cells based on single unit and field potential recordings in the geniculate (Hoffmann and Stone, 1973; Mason, 1975; Wilson et al., 1976; Mitzdorf and Singer, 1977; Dreher and Sefton, 1979). X fibers projected to layers $A$ and $\Lambda_{1}$ and, to a lesser extent, the MIN. Y fibers projected to layers $\mathrm{A}, \mathrm{A}_{1}, \mathrm{C}$, sometimes $\mathrm{C}_{1}$, and the MIN. Neither $\mathrm{X}$ nor $\mathrm{Y}$ fibers projected to layers $\mathrm{C}_{2}$ or $\mathrm{C}_{3}$. Although cells classified as X type have been recorded in layer C (Wilson et al., 1976), no X fibers were found that terminated there. However, a few $\mathrm{X}$ fibers injected by Sur and Sherman (1982) did send collaterals to $C$ as well as A.

Single axons often branched to terminate in different subdivisions of the LGNd. Thus, cell bodies with similar physiology and retinotopography, but with separate locations in the geniculate, probably receive input from identical ganglion cells. The fact that nearly all contralateral $\mathrm{Y}$ fibers projected to both layers $\mathrm{A}$ and $\mathrm{C}$ accounts partly for the absence of binocular balance in the cat; i.e., the predominance of input to the geniculate from the nasal retina (Guillery, 1979). Furthermore, it shows that the imbalance is associated with the divergence of identical information signaled from $\mathrm{Y}$ cells about the contralateral visual field. At the same time, the fact that few $\mathrm{X}$ fibers terminate in layer $\mathrm{C}$ argues that the inte- grative action of layer $\mathrm{C}$ is different from that of layer $\mathrm{A}$ (Kaas et al., 1972).

$\mathrm{X}$ and $\mathrm{Y}$ endings in the $\mathrm{A}$ layers differed in the numbers and the lateral extent of their terminal boutons. The $\mathrm{X}$ arbors usually had fewer than 1000 boutons that formed columns averaging about $150 \mu \mathrm{m}$ wide. Columns of $Y$ terminals contained from 1000 to 2000 boutons and had an average width of about $375 \mu \mathrm{m}$ or 2.5 times wider than the X columns. An important factor affecting lateral interactions in the geniculate is the overlap in the plane of the retinotopic map between the terminal fields of the afferent fibers. A rough estimate of the overlap between $Y$ fibers, at an eccentricity of $6^{\circ}$, was made from the results presented in Figure 11 and from published densities of $\mathrm{Y}$ ganglion cells on the retina. The results in Figure 11 provide the angular dimensions of a Y-on and a Y-off column in the plane of the retinotopic map (eccentricity $6^{\circ}$ ). Retinal densities of $\mathrm{Y}$ ganglion cells have been determined by Wassle et al. (1981). They found that at $6^{\circ}$ eccentricity the density of Y-on ( $\alpha$-on) cells is about $28 \mathrm{~mm}^{-2}$, or in angular measure, about 1.5 $\mathrm{deg}^{-2}$. Similarly, Y-off ( $\alpha$-off) cells at $6^{\circ}$ occur at a density of about $35 \mathrm{~mm}^{-2}$ or about $1.8 \mathrm{deg}^{-2}$. Assuming that the $\alpha$ cells are identical to $\mathrm{Y}$ cells and that they all project to the A layers, then the angular density of the $\mathrm{Y}$ afferents terminating in the A layers should be the same as the angular density of $\mathrm{Y}$ ganglion cells on the retina. From the density and size of the afferent terminations, it is possible to estimate the overlap between adjacent columns of $Y$-on and $Y$-off terminal boutons. The overlap is illustrated by the diagrams in Figure 15. The elliptically shaped envelopes are outlines of the Y-on and Yoff columns from Figure 11. Duplicates of each envelope (dashed lines) were displaced from the originals (one to the right and one downward) to represent column densities of $1.5 \mathrm{deg}^{-2}$ for the Y-on columns and $1.8 \mathrm{deg}^{-2}$ for the Y-off columns. The columns appear to overlap extensively, about $60 \%$ in the direction of azimuth (mediolaterally) and about $80 \%$ in the direction of visual elevation (anteroposteriorly). Perhaps the elliptical crosssections of the Y columns, as well as differences in their overlap in the directions of azimuth and elevation, are related to tasks such as stereopsis and conjugate eye movements. These tasks place different requirements on how information is processed in relation to horizontal and vertical directions. The elliptical geometry of the $\mathrm{Y}$ columns is interesting in light of the recent observations of Silverman et al. (1983) showing that the retinotopic map in area 17 in the cat is "distorted" by elongation, like the $\mathrm{Y}$ columns, in the direction of visual elevation.

The patterns in the shapes and densities of the terminal distributions across layers $\mathrm{A}$ and $\mathrm{A}_{1}$ suggest that the layers are not functionally homogeneous across their widths. There are differences, in both the densities of the $\mathrm{X}$ and $\mathrm{Y}$ terminals and the lateral spreads of the $\mathrm{X}$, $\mathrm{Y}$-on, and Y-off terminal columns. Differences in the balance of $\mathrm{X}$ and $\mathrm{Y}$ input across the layers have been reported previously by Mitzdorf and Singer (1977) on the basis of current source density analysis. Their conclusion that $\mathrm{X}$ and $\mathrm{Y}$ inputs are partially segregated between the dorsal and ventral portions of the $A$ layers is supported by the results presented here. There have also been reports, from multi-unit recordings, that on- 

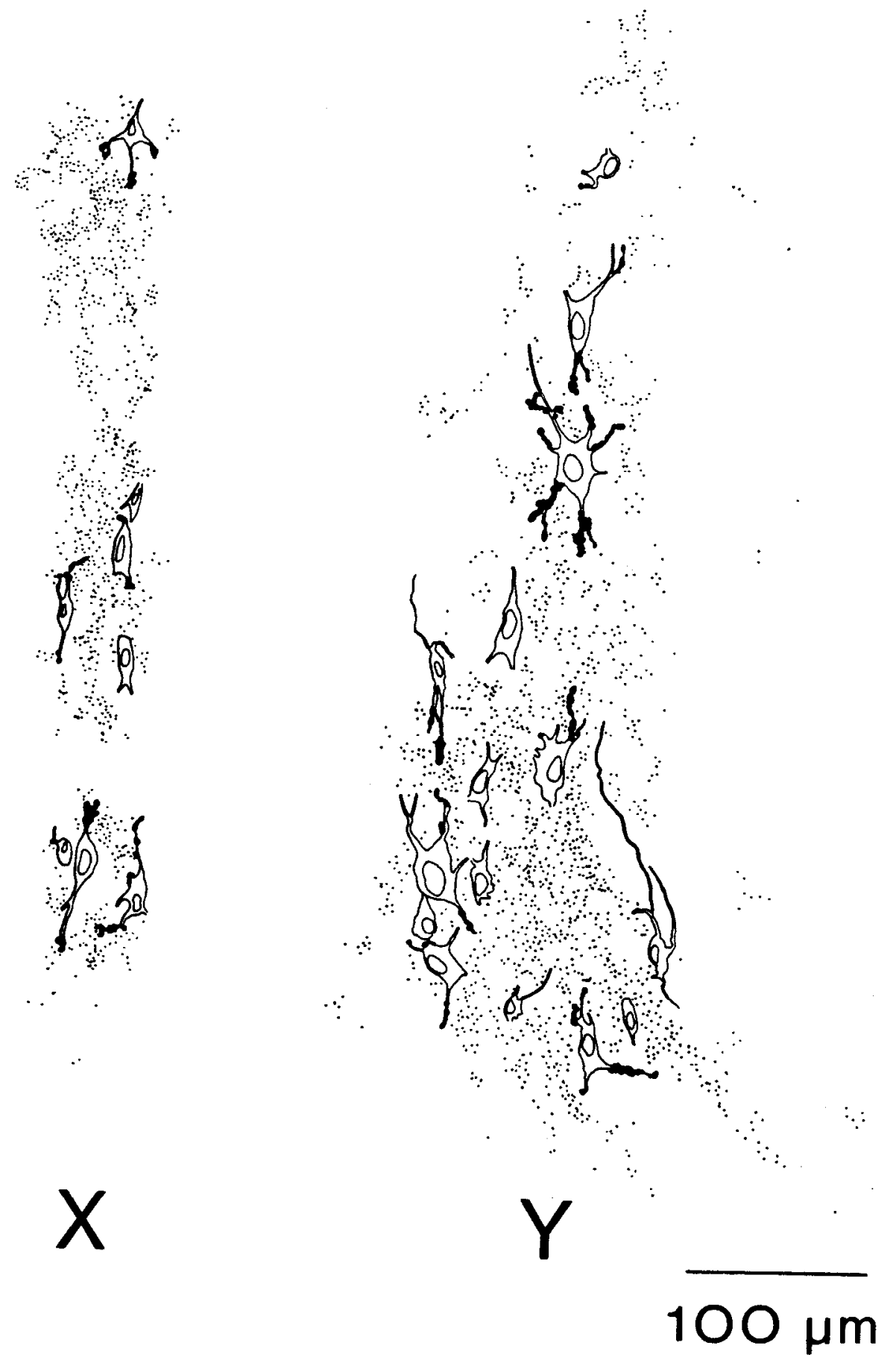

Figure 14. Reconstructions of the transneuronally stained neurons and the terminal distributions of a single contralateral $\mathrm{X}$-on axon and a single ipsilateral $\mathrm{Y}$-off axon. The terminal boutons that appeared to be in contact with the cells' dendrites are drawn as solid black figures whereas the rest are represented by dots. Both reconstructions were made from parasagittal sections. 

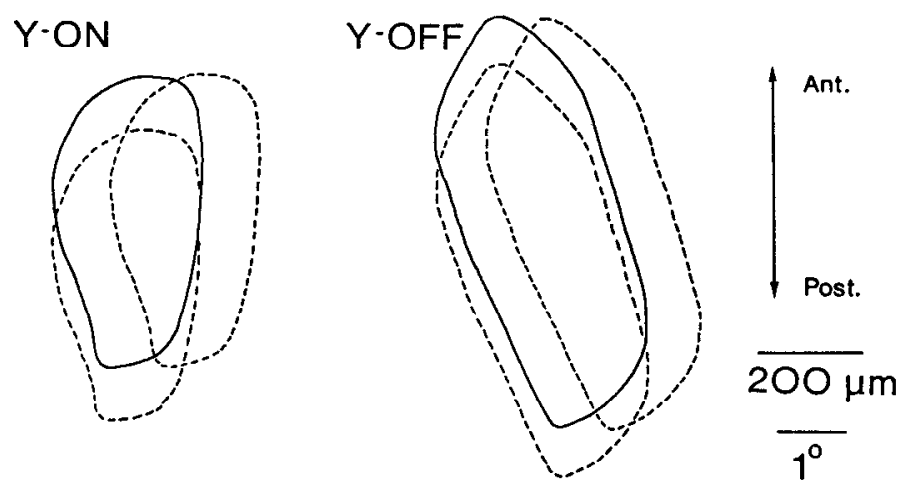

Figure 15. Schematic diagrams showing the size and estimated overlap of adjacent terminal fields from Y-on and Y-off fibers at about $6^{\circ}$ eccentricity. The envelopes represent the terminal fields of single fibers in the retinotopic plane of layer A. The shapes and dimensions of the envelopes were taken from Figure 11. The overlap between the envelopes represents an estimate based on retinal densities of the Y-on and Y-off ganglion cells (see "Discussion" for details).

responses are more common near the tops of the layers (Seneviratne and Whitteridge, 1962; Bowling, 1983; Bowling and Schoel, 1983). Although this has not been supported by single unit recordings (Sanderson, 1971), the relative weighting of $\mathrm{Y}$-on terminals over $\mathrm{Y}$-off terminals in the upper halves of the layers (35\% of $\mathrm{Y}$-on compared to $21 \%$ of $\mathrm{Y}$-off terminals) lends the idea some support. It is interesting in this regard that two other carnivores, mink and ferret (LeVay and McConnell, 1982; Stryker and Zahs, 1983), as well as a primate (Schiller and Malpeli, 1978), have also been reported to show dorsal displacements of the ON pathway in the geniculate. Finally, the variable widths of the $\mathrm{Y}$ terminal columns across the layers ought to give rise to differences in spatial integration at different depths. Evidence that spatial properties of geniculate cells do in fact change with depth has recently been reported by Movshon (1981). He found that $Y$ cells in the upper parts of $A$ and $A_{1}$ respond to gratings of higher spatial frequency than do $\mathrm{Y}$ cells at the bottoms of the layers. It would be interesting to know if there are any variations with depth between $\mathrm{Y}$-on and $\mathrm{Y}$-off cells in light of the differences in the profiles of $\mathrm{Y}$-on and $\mathrm{Y}$-off afferent columns across the layers.

\section{References}

Adams, J. (1981) Heavy metal intensification of DAB-based HRP reaction product. J. Histochem. Cytochem. 29: 775 .

Baker, R., and A. Grantyn (1982) Transneuronal transport of HRP following intra-axonal injection of cat vestibular neurons. Soc. Neurosci. Abstr. 8: 787.

Bowling, D. B. (1983) Responses to light at different depths in the A layers of the cat's lateral geniculate nucleus. Invest. Ophthalmol. Vis. Sci. 24 (Suppl): 265.

Bowling, D. B., and C. R. Michael (1980) Projections of single physiologically characterized optic tract fibres in cat. Naturc 286: 899-902.

Bowling, D. B., and W. M. Schoel (1983) Functional organization across single layers of the lateral geniculate nucleus in the cat. Soc. Neurosci. Abstr. 9: 1046.

Campbell, R. C. (1974) Statistics for Biologists, Ed. 2, Cambridge University Press, New York.
Cleland, B. G., M. W. Dubin, and W. R. Levick (1971) Sustained and transient neurones in the cat's retina and lateral geniculate nucleus. J. Physiol. (Lond.) 217: 473-496.

Cleland, B. G., T. H. Harding, and W. R. Levick (1979) Visual resolution and receptive field size: Examination of two kinds of cat retinal ganglion cell. Science 205: 1015-1017.

Dreher, B., and A. J. Sefton (1979) Properties of neurones in cat's dorsal lateral geniculate nucleus: A comparison between medial interlaminar and laminated parts of the nucleus. J. Comp. Neurol. 183: 47-64.

Enroth-Cugell, C., and J. G. Robson (1966) The contrast sensitivity of retina ganglion cells in the cat. J. Physiol. (Lond.) 187: $517-552$.

Friedlander, M. J., C. S. Lin, L. R. Stanford, and S. M. Sherman (1981) Morphology of functionally identified neurons in lateral geniculate nucleus of the cat. J. Neurophysiol. 46: 80129.

Fukuda, Y. (1971) Receptive field organization of cat optic nerve fibers with special reference to conduction velocity. Vision Res. 11: 209-226.

Guillery, R. W. (1966) A study of Golgi preparations from the dorsal lateral geniculate nucleus of the cat. J. Comp. Neurol. 238: $21-50$.

Guillery, R. W. (1979) A speculative essay on geniculate lamination and its development. Prog. Brain Res. 51: 403-418.

Hamasaki, D. I., and V. G. Sutija (1979) Classification of cat retinal ganglion cells into $\mathrm{X}$ - and $\mathrm{Y}$-cells with a contrast reversal stimulus. Exp. Brain Res. 35: 25-36.

Hochstein, S., and R. M. Shapley (1976) Quantitative analysis of retinal ganglion cell classifications. J. Physiol. (Lond.) 262: 237-264.

Hoffmann, K. P., and J. Stone (1973) Central termination of $\mathrm{W}-, \mathrm{X}-$, and $\mathrm{Y}$-type ganglion cell axons from cat retina. Brain Res. 49: 500-501.

Hongo, T., N. Kudo, M. Yamashita, N. Ishizuka, and H. Mannen (1981) Transneuronal passage of intra-axonally injected horseradish peroxidase (HRP) from group Ib and II fibers into the secondary neurons in the dorsal horn of the cat spinal cord. Biomed. Res. 2: 722-727.

Kaas, J. H., R. W. Guillery, and J. M. Allman (1972) Some principles of organization in the dorsal lateral geniculate nucleus. Brain Behav. Evol. 6: 253-299.

LeVay, S., and S. K. McConnel (1982) ON and OFF layers in the lateral geniculate nucleus of the mink. Nature 300:350 351.

Mason, R. (1975) Cell properties in the medial interlaminar nucleus of the cal's lateral geniculate complex in relation to the transient/sustained classification. Exp. Brain Res. 22: $327-329$.

Mason, C. A., and J. A. Robson (1979) Morphology of retinogeniculate axons in the cat. Neuroscience 4: 79-97.

Mitzdorf, U., and W. Singer (1977) Laminar segregation of afferents to lateral geniculate nucleus of the cat: An analysis of current source density. J. Neurophysiol. 40: 1227-1244.

Movshon, J. A. (1981) Functional architecture in the cat's lateral geniculate nucleus. Invest. Ophthalmol. Vis. Sci. 20 (Suppl): 14 .

Sanderson, J. J. (1971) The projection of the visual field to the lateral geniculate and medial interlaminar nuclei in the cat. J. Comp. Neurol. 143: 101-118.

Schiller, P. H., and J. G. Malpeli (1978) Functional specificity of lateral geniculate nuclcus laminae of the rhesus monkey. J. Neurophysiol. 41: 788-797.

Seneviratne, K. N., and D. Whitteridge (1962) Visual evoked responses in the lateral geniculate nucleus. Electroencephalogr. Clin. Neurophysiol. 14: 785.

Silverman, M. S., R. B. H. Tootell, E. Switkes, and R. L. DeValois (1983) The retinotopic organization of cat striate 
cortex. Invest. Opthal. Vis. Science 24 (Suppl): March 1983. Stone, J., and Y. Fukuda (1974) Properties of cat retinal ganglion cells: A comparison of W-cells with X-and Y-cells. J. Neurophysiol. 37: $722-748$.

Stryker, M. P., and K. R. Zahs (1983) ON and OFF sublaminae in the lateral geniculate nucleus of the ferret. Invest. Ophthalmol. Vis. Sci. 24 (Suppl.): 265.

Sur, M., and S. M. Sherman (1982) Retinogeniculate terminations in cats: Morphological differences between $\mathrm{X}$ and $\mathrm{Y}$ cell axons. Science 218: 389-391.
Triller, A., and H. Korn (1981) Interneural transfer of horseradish peroxidase associated with exo-endocytotic activity on adjacent membranes. Exp. Brain Res. 43: 233-236.

Wassle, H., L. Peichl, and B. B. Boycott (1981) Morphology and topography of on- and off-alpha cells in the cat retina. Proc. R. Soc. Lond. Biol. 212: 157-175.

Wilson, P. D., M. H. Rowe, and J. Stone (1976) Properties of relay cells in cat's lateral geniculate nucleus: A comparison of W-cells with X- and Y cells. J. Neurophysiol. 39: 11931209 . 